\title{
Syntheses and Biological Evaluation of Novel Hydroxamic Acid Derivatives Containing Purine Moiety as Histone Deacetylase Inhibitors
}

\author{
Zhaoxing Xu, ${ }^{\#}$ Yongchao Yang, ${ }^{\#}$ Xi Mai,* Bin Liu, Yuanzhen Xiong, Lihuang Feng, Yijing Liao, \\ Yu Zhang, Huanlu Wang, Leiting Ouyang, and Shuhao Liu
}

School of Pharmaceutical Sciences, Nanchang University; Nanchang 330006, P. R. China.

Received December 11, 2017; accepted January 25, 2018

\begin{abstract}
The novel hydroxamates containing purine scaffold were designed, synthesized and screened for their biological activities as histone deacetylase (HDAC) inhibitors. Some of them exhibited excellent acti-HDACs activities and antiproliferative activities, the most promising compound was $7 \mathrm{~m}^{\prime}$. Western blot analysis indicated the compounds $7 \mathrm{f}^{\prime}, 7 \mathrm{l}^{\prime}, 7 \mathrm{~m}^{\prime}, 7 \mathrm{o}^{\prime}$ could increase histone $\mathrm{H3}$ acetylation levels in HCT116 and $\mathrm{K562}$ cell lines, and $7 \mathrm{~m}^{\prime}$ increased the level of acetyl histone $\mathrm{H3}$ in a dose-dependent manner, which is similar to the behavior of suberoylanilide hydroxamic acid (SAHA). Molecular docking study revealed that the conformation of $7 \mathrm{~m}^{\prime}$ in the active site of HDAC2 was similar to positive drug SAHA, which were oriented with the hydroxamic acid towards the catalytic center and formed metal binding with zinc ion.
\end{abstract}

Key words hydroxamic acid; purine; histone deacetylase; antiproliferative; Western blot analysis

At present a large number of researches indicate that tumorigenesis is closely related to histone deacetylases (HDACs) because they trigger the abnormal transcription of crucial genes that control essential cell functions, namely proliferation, cell cycle regulation and apoptosis. ${ }^{1,2)}$ It also imparts its role in several genome functions such as DNA repair, chromatin assembly and recombination. Nearly 18 HDAC isoforms have been identified in humans. They have been categorized into five classes based on their cellular location, size, number of catalytic pockets and homology to yeast prototypes. ${ }^{3,4)}$ The enzymes of classes I (HDAC 1, 2, 3 and 8), IIa (HDACs 4, $5,7,9)$, IIb (HDACs 6, 10) and IV (HDAC 11) are all $\mathrm{Zn}^{2+}$ dependent metalloproteases, whereas the class III HDACs (SIRT1-7) are oxidized form of nicotinamide adenine dinucleotide $\left(\mathrm{NAD}^{+}\right)$dependent. ${ }^{5-7)}$ It has been suggested that $\mathrm{Zn}^{2+}$-dependent HDACs, especially class I and class II isozyme, are closely related to tumorigenesis and development, and inhibition of HDACs can result in proliferation inhibition, apoptosis, cellular differentiation and migration inhibition of tumor cells. ${ }^{8-10)}$ Therefore, HDACs inhibitors (HDACi) against $\mathrm{Zn}^{2+}$-dependent HDACs have been developed extensively. ${ }^{11,12)}$ Over the past years, the U.S Food and Drug Administration has approved several HDACi, including suberoylanilide hydroxamic acid (SAHA, Vorinostat) and FK-228 (romidepsin) for the treatment of refractory cutaneous T-cell lymphoma, ${ }^{13,14)}$ PXD101 (belinostat) for treatment of refractory bperipheral T-cell lymphoma, ${ }^{15}$ ) and LBH589 (panobinostat) for the treatment of multiplemyeloma. ${ }^{16)}$ Because of strong zinc-chelating ability, hydroxamic acid remains among the most potent and popular zinc ion binding group (ZBG) reported for inhibition of Class I HDACs. ${ }^{17)}$ Among approved drugs, SAHA, PXD101, LBH589 both possess a hydroxamic acid moiety. Despite the variety of structural characteristics, most HDACs inhibitors, including hydroxamates, can be considered to have a common pharmacophore, which mainly contains three parts: a zinc ion binding group (ZBG) and a cap group which makes contacts

\footnotetext{
${ }^{\#}$ These authors contributed equally to this work.

with the amino acid residues on the rim of the enzymatic active site, joined by a linker domain with proper length. ${ }^{18,19)}$

Many purine compounds have been described as anticancer derivatives, such as early 6-mercaptopurine have been extensively used in clinical as an anti-tumor drug through inhibiting the synthesis of nucleic acid in tumor cells, ${ }^{20,21)}$ and then Nelarabine, Fludarabine, Cladribine, Clofarabine were discovered as anti-tumor drugs. ${ }^{22-25)}$ Substituted at 2, 6, 8 and 9 positions have been the focus of structural modifications of the purine ring. Both mono-substituted and 2, 6, 8, 9 positions multi-substituted derivatives show multiple mechanism of action. ${ }^{26-30)}$ In consideration of excellent characteristics of purine derevatives on anti-tumor, the combination of purine and hydroxamic acid was expected to exert their respective superiority, the novel series of purine-containing hydroxamic acids were designed and synthesized, wherein purine was selected as the cap domain based on the fact that most potent HDACi possessed aromatic or heteroaromatic rings in their cap groups ${ }^{12,31)}$ expecting that purine scaffold could not only form special interation with the rim of the enzymatic active site but also exert synergistic effects on anti-tumor due to its multiple biological activities. Of target compounds, one is both 6-substituted purine hydroxamic acids and 6-substituted purine hydroxycarbamides containing hydroxyurea pharmacophore. Our group has made great efforts to develop novel hydroxycarbamides to evaluate their anticancer activity, ${ }^{32-35)}$ and found that some hydroxycarbamides possessed potent antitumor activity. To explore the possibility of synergistic effects, we introduced aliphatic diamines to 6-position of purine as linker and synthesized 6-substituted purine hydroxycarbamides, namely, 6-substituted purine hydroxamic acids. In addition, based on the aliphatic carbonchain linker of SAHA, we introduced aliphatic carbonchain to 9-position of purine and synthesized 9-substituted purine hydroxamic acids (Fig. 1). The HDACs inhibitory activities, anticancer activities and effect of histone $\mathrm{H} 3$ acetylation of these novel compounds were comprehensively investigated in this paper. 

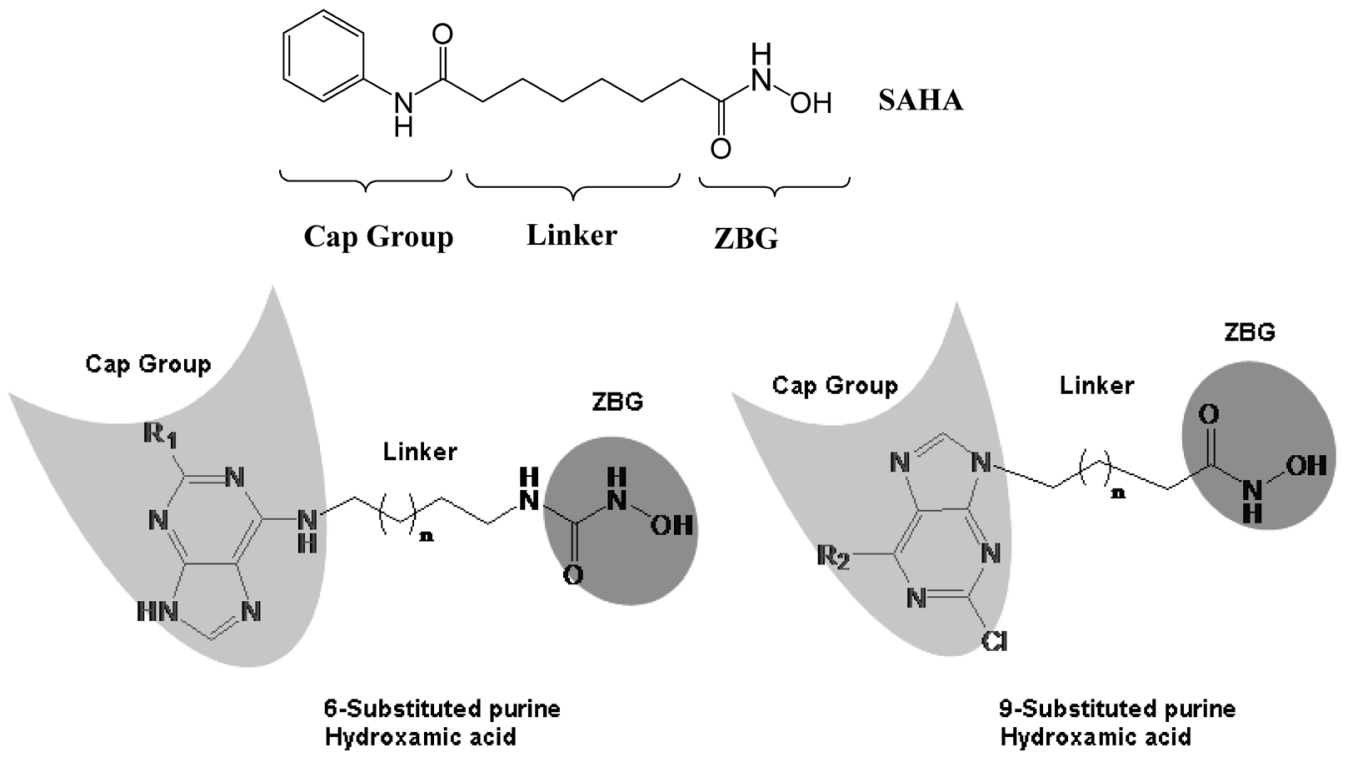

Fig. 1. Design Strategy of Purine-Containing Hydroxamic Acid Derivatives<smiles>NNc1nc(N)c2nc(N)nc(Cl)c2n1</smiles>

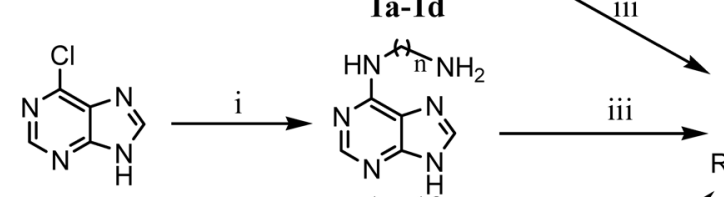<smiles>[AlH2]</smiles>

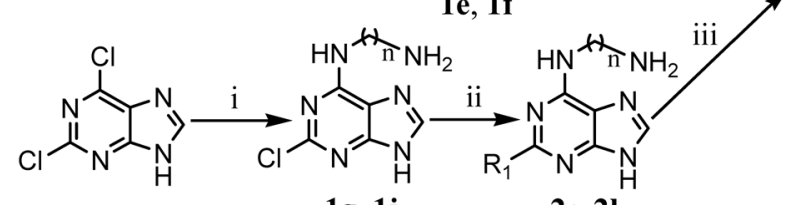

$1 \mathrm{~g}, 1 \mathrm{j}$

2g-2l

$$
\begin{aligned}
& \text { a: } n=2, \mathrm{R}_{1}=\mathrm{NH}_{2} ; \quad \text { e: } \mathrm{n}=2, \mathrm{R}_{1}=\mathrm{H} ; \quad \mathrm{i}: \mathrm{n}=2, \mathrm{R}_{1}=4-\mathrm{HO}-\mathrm{PhNH} \text {; } \\
& \mathbf{b}: \mathrm{n}=3, \mathrm{R}_{1}=\mathrm{NH}_{2} ; \quad \mathbf{f : n}=4, \mathrm{R}_{1}=\mathrm{H} ; \quad \mathrm{j}: \mathrm{n}=3, \mathrm{R}_{1}=4-\mathrm{CH}_{3}-\mathrm{PhNH} \text {; } \\
& \text { c: } n=4, \mathrm{R}_{1}=\mathrm{NH}_{2} ; \quad \mathbf{g}: \mathrm{n}=2, \mathrm{R}_{1}=\mathrm{PhNH} ; \quad \mathbf{k}: \mathrm{n}=3, \mathrm{R}_{1}=4-\mathrm{HO}-\mathrm{PhNH} \text {; } \\
& \text { d: } n=6, \mathrm{R}_{1}=\mathrm{NH}_{2} ; \quad \text { h:n=2, } \mathrm{R}_{1}=4-\mathrm{CH}_{3}-\mathrm{PhNH} ; \quad \mathrm{l}: \mathrm{n}=3, \mathrm{R}_{1}=4-\mathrm{CH}_{3} \mathrm{O}-\mathrm{PhNH} \text {. }
\end{aligned}
$$

Reagents and conditions: (i) Diamine, TEA, $n$-butanol, reflux, 6h; (ii) TFA, aromaticamine, $120^{\circ} \mathrm{C}, 12 \mathrm{~h}$. (iii) 4-Nitrophenyl chloroformate, $\mathrm{NaHCO}{ }_{3}$, $\mathrm{H}_{2} \mathrm{O}$ : acetonitrile $=2: 3,0^{\circ} \mathrm{C}, 0.5-1 \mathrm{~h}$. (iv) $\mathrm{NH}_{2} \mathrm{OH} \cdot \mathrm{HCl}, \mathrm{NaOH}, \mathrm{MeOH}, 55^{\circ} \mathrm{C}, 5 \mathrm{~h}$.

Chart 1

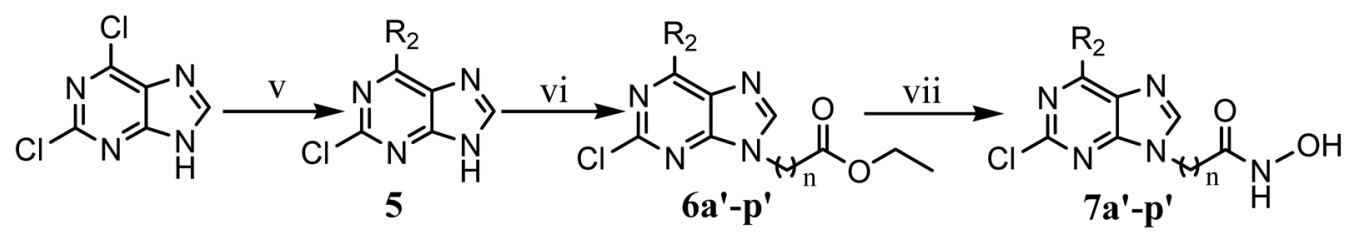

$$
\begin{array}{lll}
\mathbf{5 :} \mathbf{b}^{\prime}: \mathrm{R}_{2}=\mathrm{CH}_{3} \mathrm{NH} ; & \mathbf{6 , 7 :} \mathbf{a}^{\prime}: \mathrm{n}=3, \mathrm{R}_{2}=\mathrm{Cl} ; & \mathbf{j}^{\prime}: \mathrm{n}=7, \mathrm{R}_{2}=\mathrm{Cl} ; \\
\mathbf{c}^{\prime}: \mathrm{R}_{2}=\mathrm{CH}_{3} \mathrm{CH}_{2} \mathrm{NH} ; & \mathbf{b}^{\prime}: \mathrm{n}=3, \mathrm{R}_{2}=\mathrm{CH}_{3} \mathrm{NH} ; & \mathbf{k}^{\prime}: \mathrm{n}=7, \mathrm{R}_{2}=\mathrm{CH}_{3}\left(\mathrm{CH}_{2}\right)_{2} \mathrm{NH} ; \\
\mathbf{d}^{\prime}: \mathrm{R}_{2}=\mathrm{CH}_{3}\left(\mathrm{CH}_{2}\right)_{2} \mathrm{NH} ; & \mathbf{c}^{\prime}: \mathrm{n}=3, \mathrm{R}_{2}=\mathrm{CH}_{3} \mathrm{CH}_{2} \mathrm{NH} ; & \mathbf{l}^{\prime}: \mathrm{n}=7, \mathrm{R}_{2}=\mathrm{PhNH}^{-} ; \\
\mathbf{e}^{\prime}: \mathrm{R}_{2}=\mathrm{PhNH} ; & \mathbf{d}^{\prime}: \mathrm{n}=3, \mathrm{R}_{2}=\mathrm{CH}_{3}\left(\mathrm{CH}_{2}\right)_{2} \mathrm{NH} ; & \mathbf{m}^{\prime}: \mathrm{n}=7, \mathrm{R}_{2}=4-\mathrm{CH}_{3}-\mathrm{PhNH} ; \\
\mathbf{f}^{\prime}: \mathrm{R}_{2}=4-\mathrm{CH}_{3}-\mathrm{PhNH} ; & \mathbf{e}^{\prime}: \mathrm{n}=3, \mathrm{R}_{2}=\mathrm{PhNH} ; & \mathbf{n}^{\prime}: \mathrm{n}=7, \mathrm{R}_{2}=4-\mathrm{CH}_{3} \mathrm{O}-\mathrm{PhNH} ; \\
\mathbf{g}^{\prime}: \mathrm{R}_{2}=4-\mathrm{CH}_{3} \mathrm{O}-\mathrm{PhNH} ; & \mathbf{f}^{\prime}: \mathrm{n}=3, \mathrm{R}_{2}=4-\mathrm{CH}_{3}-\mathrm{PhNH} ; & \mathbf{o}^{\prime}: \mathrm{n}=7, \mathrm{R}_{2}=4-\mathrm{Cl}-\mathrm{PhNH} ; \\
\mathbf{h}^{\prime}: \mathrm{R}_{2}=4-\mathrm{Cl}-\mathrm{PhNH} ; & \mathbf{g}^{\prime}: \mathrm{n}=3, \mathrm{R}_{2}=4-\mathrm{CH}_{3} \mathrm{O}-\mathrm{PhNH} ; & \mathbf{p}^{\prime}: \mathrm{n}=7, \mathrm{R}_{2}=4-\mathrm{HO}-\mathrm{PhNH} \\
\mathbf{i}^{\prime}: \mathrm{R}_{2}=4-\mathrm{HO}-\mathrm{PhNH} ; & \mathbf{h}^{\prime}: \mathrm{n}=3, \mathrm{R}_{2}=4-\mathrm{Cl}-\mathrm{PhNH} ; & \\
& \mathbf{i}^{\prime}: \mathrm{n}=3, \mathrm{R}_{2}=4-\mathrm{HO}-\mathrm{PhNH} ; &
\end{array}
$$


Table 1. The HDACs Inhibitory Activities of Compounds

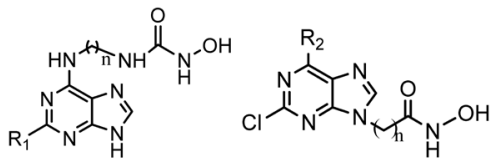

\begin{tabular}{|c|c|c|c|c|}
\hline & \multicolumn{2}{|c|}{ Compounds 4} & \multicolumn{2}{|c|}{ Compounds 7} \\
\hline Compound & $\mathrm{R}_{1}$ & $\mathrm{R}_{2}$ & $\mathrm{n}$ & $\mathrm{IC}_{50}$ of $\mathrm{HDACs}(\mathrm{nM})$ \\
\hline $4 a$ & $-\mathrm{NH}_{2}$ & - & 2 & $123.0 \pm 13.5$ \\
\hline $4 b$ & $-\mathrm{NH}_{2}$ & - & 3 & $67.7 \pm 4.6$ \\
\hline $4 c$ & $-\mathrm{NH}_{2}$ & - & 4 & $28.6 \pm 8.2$ \\
\hline $4 d$ & $-\mathrm{NH}_{2}$ & - & 6 & $18.4 \pm 2.2$ \\
\hline $4 e$ & $\mathrm{H}$ & - & 2 & $40.4 \pm 3.9$ \\
\hline $4 f$ & $\mathrm{H}$ & - & 4 & $52.4 \pm 2.1$ \\
\hline $4 \mathrm{~g}$ & PhNH- & - & 2 & $>1000$ \\
\hline $4 h$ & 4- $\mathrm{CH}_{3}-\mathrm{PhNH}-$ & - & 2 & $>1000$ \\
\hline $4 i$ & 4-HO-PhNH- & - & 2 & $>1000$ \\
\hline $4 j$ & 4- $\mathrm{CH}_{3}-\mathrm{PhNH}-$ & - & 3 & $341.6 \pm 17.2$ \\
\hline $4 k$ & 4-HO-PhNH- & - & 3 & $>1000$ \\
\hline 41 & 4- $\mathrm{CH}_{3} \mathrm{O}-\mathrm{PhNH}-$ & - & 3 & $>1000$ \\
\hline $7 a^{\prime}$ & $\mathrm{Cl}$ & $\mathrm{Cl}$ & 3 & $71.8 \pm 3.9$ \\
\hline $7 b^{\prime}$ & $\mathrm{Cl}$ & $\mathrm{CH}_{3} \mathrm{NH}-$ & 3 & $67.2 \pm 7.0$ \\
\hline $7 c^{\prime}$ & $\mathrm{Cl}$ & $\mathrm{CH}_{3} \mathrm{CH}_{2} \mathrm{NH}-$ & 3 & $21.9 \pm 1.4$ \\
\hline $7 d^{\prime}$ & $\mathrm{Cl}$ & $\mathrm{CH}_{3}\left(\mathrm{CH}_{2}\right)_{2} \mathrm{NH}-$ & 3 & $44.1 \pm 2.6$ \\
\hline $7 e^{\prime}$ & $\mathrm{Cl}$ & PhNH- & 3 & $328.3 \pm 24.5$ \\
\hline $7 f^{\prime}$ & $\mathrm{Cl}$ & 4- $\mathrm{CH}_{3}-\mathrm{PhNH}-$ & 3 & $17.8 \pm 3.3$ \\
\hline $7 \mathbf{g}^{\prime}$ & $\mathrm{Cl}$ & 4- $\mathrm{CH}_{3} \mathrm{O}-\mathrm{PhNH}-$ & 3 & $142.5 \pm 6.5$ \\
\hline $7 \mathbf{h}^{\prime}$ & $\mathrm{Cl}$ & 4-Cl-PhNH- & 3 & $19.2 \pm 5.6$ \\
\hline $7 \mathbf{i}^{\prime}$ & $\mathrm{Cl}$ & 4-HO-PhNH- & 3 & $138.2 \pm 6.0$ \\
\hline $7 \mathbf{j}^{\prime}$ & $\mathrm{Cl}$ & $\mathrm{Cl}$ & 7 & $47.2 \pm 2.7$ \\
\hline $7 k^{\prime}$ & $\mathrm{Cl}$ & $\mathrm{CH}_{3}\left(\mathrm{CH}_{2}\right)_{2} \mathrm{NH}-$ & 7 & $27.9 \pm 5.1$ \\
\hline $71^{\prime}$ & $\mathrm{Cl}$ & PhNH- & 7 & $39.5 \pm 7.5$ \\
\hline $7 m^{\prime}$ & $\mathrm{Cl}$ & 4- $\mathrm{CH}_{3}-\mathrm{PhNH}-$ & 7 & $15.3 \pm 1.9$ \\
\hline $7 n^{\prime}$ & $\mathrm{Cl}$ & 4- $\mathrm{CH}_{3} \mathrm{O}-\mathrm{PhNH}-$ & 7 & $38.0 \pm 4.6$ \\
\hline $70^{\prime}$ & $\mathrm{Cl}$ & 4-Cl-PhNH- & 7 & $18.1 \pm 2.1$ \\
\hline $7 \mathbf{p}^{\prime}$ & $\mathrm{Cl}$ & 4-HO-PhNH- & 7 & $16.4 \pm 6.7$ \\
\hline SAHA & & & & $20.7 \pm 2.2$ \\
\hline PXD101 & & & & $19.9 \pm 3.0$ \\
\hline
\end{tabular}

\section{Results and Discussion}

Chemistry The starting materials 6-chloro-9H-purine, 6-chloro-9H-purin-2-amine and 2,6-dichloro-9H-purine are commercially available. The target compounds $\mathbf{4 a}-\mathbf{4 l}$ and $7 \mathbf{a}^{\prime}-7 \mathbf{p}^{\prime}$ were synthesized following the procedures described in Chart 1 and 2.

The intermediates $\mathbf{1} \mathbf{a}-\mathbf{1 g}, \mathbf{1 j}$ were synthesized through a nucleophilic substitution reaction of starting materials with different diamine in $n$-butanol. Intermediates $\mathbf{2 g} \mathbf{g} \mathbf{2 l}$, which were substituted by aromatic amine at position 2, were synthesized using $\mathbf{1 g}$ and $\mathbf{1 j}$, which should be catalyzed by trifluoroacetic acid (TFA). In the presence of $\mathrm{NaHCO}_{3}$, compounds 1a-1f and $\mathbf{2 g}-\mathbf{2 l}$ were treated with 4-nitrophenyl chloroformate to give $\mathbf{3 a}-\mathbf{3 l} \mathbf{l},{ }^{33,34)}$ and then $\mathbf{3 a}-\mathbf{3 l}$ were converted to target compounds $4 \mathbf{a}-\mathbf{4 l}$ in the presence of $\mathrm{NaOH}$ in anhydrous methanol with hydroxylamine hydrochloride (Chart 1).

Intermediates 5 could be obtained by reaction of 2,6-dichloro- $9 H$-purine and different aliphatic amine and aromatic amine, their synthesis methods were same as that of $\mathbf{1 a}-\mathbf{1 d}$. In the presence of $\mathrm{K}_{2} \mathrm{CO}_{3}$, compounds 5 were treated with ethyl 4-bromobutanoate or ethyl 8-bromooctanoate in DMF at room temperature for overnight to give $\mathbf{6} \mathbf{a}^{\prime}-\mathbf{6} \mathbf{p}^{\prime}$, and then converted to target compounds $7 \mathbf{a}^{\prime}-7 \mathbf{p}^{\prime}$ in the presence of $\mathrm{CH}_{3} \mathrm{ONa}$ in anhydrous methanol with hydroxylamine hydrochloride (Chart 2).

HDACs Inhibition Assays In vitro bioactivity evaluation 
of compounds $\mathbf{4} \mathbf{a}-\mathbf{4 l}$ and $\mathbf{7} \mathbf{a}^{\prime}-\mathbf{7} \mathbf{p}^{\prime}$ were performed by HDACs activity assays using an HDAC Colorimetric Assay/Drug Discovery kit (AK501, Enzo Biochem Inc.) (mainly HDAC 1\&2). Assays were performed according to its product manual, and SAHA was used as positive control. The test results were presented in Table 1.

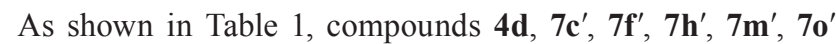
and $\mathbf{7} \mathbf{p}^{\prime}$ showed comparable inhibitory activity with SAHA and PXD101. The majority of the compounds 7 showed interesting activity, among them, four compounds $\mathbf{7} \mathbf{m}^{\prime}, \mathbf{7} \mathbf{p}^{\prime}, \mathbf{7} \mathbf{f}^{\prime}$ and $\mathbf{7 \mathbf { o } ^ { \prime }}$ exhibited very potent inhibitory activities with the $\mathrm{IC}_{50}$ values of 15.3, 16.4, 17.8 and $18.1 \mathrm{~nm}$. Compounds $\mathbf{4 g - 4 1}$, which possesses aromatic groups at position 2 of purine, showed poor activities, suggesting the substitution with bulky groups on purine C2-position was unfavorable for the inhibitory activities. In general, compounds 7 bearing aliphatic carbonchain linkers were shown to be more potent aganist HDACs than compounds $\mathbf{4}$ bearing aliphatic diamines linkers, suggesting 9-substituted purine hydroxamic acids may be superior to the 6-substituted purine hydroxycarbamides in anti-

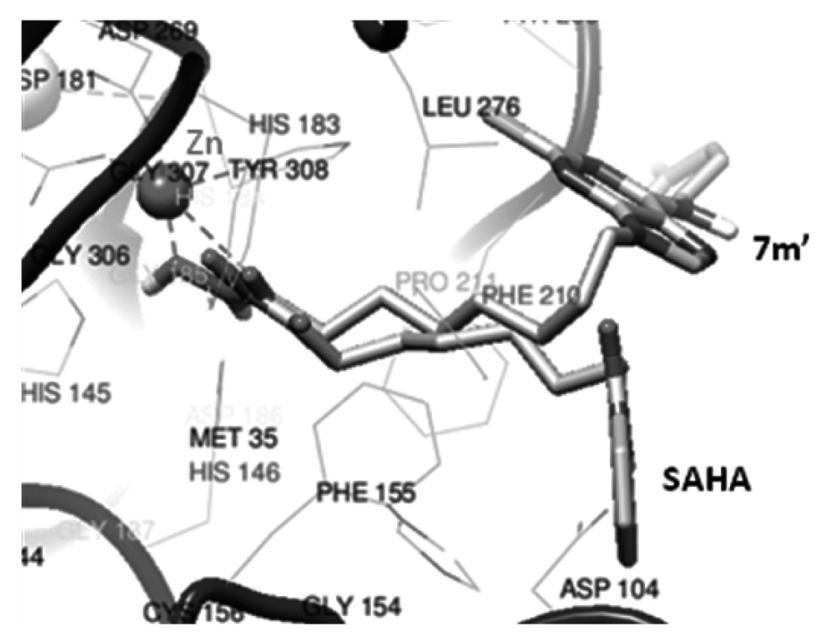

Fig. 2. The Docking Mode Comparison of Compounds SAHA, 7m'

A

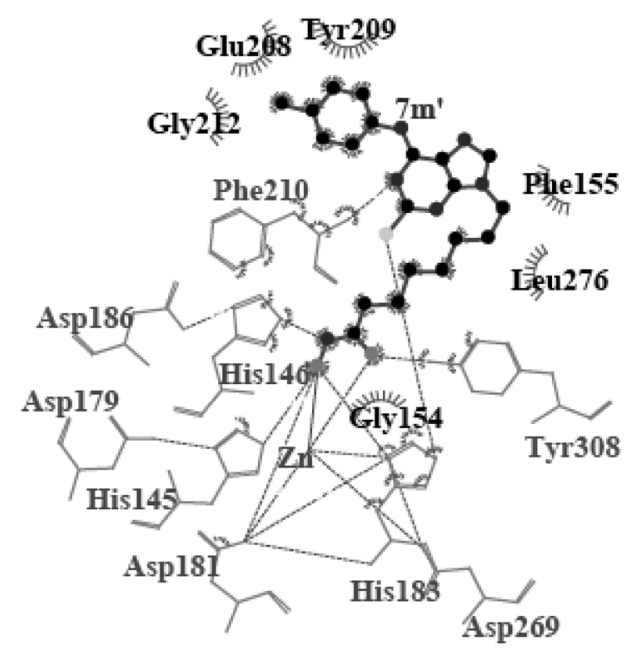

HDACs activities. On the other hand, the length of the linker had also an effect on anti-HDACs activities. Using longer linkers (compounds $\mathbf{7} \mathbf{j}^{\prime}-\mathbf{7} \mathbf{p}^{\prime}$ ) in contrast to shorter linkers ana$\operatorname{logs}$ (compounds $\mathbf{7} \mathbf{a}^{\prime}$ and $\mathbf{7} \mathbf{d}^{\prime}-\mathbf{7} \mathbf{i}^{\prime}$ ) would increase the biological activities, and so were compouns $\mathbf{4 a}-\mathbf{4 d}$, their activities increased with the extension of linker.

Docking Study Docking studies were performed to gain insight into the protein-inhibitor interactions within the enzyme binding sites. The crystal structure of HDAC2 in complex with representative hydroxamate SAHA was used for docking experiments of target compounds. ${ }^{36)}$ The 3D crystal structure of HDAC2 (PDB ID: 4LXZ) was collected from RCSB-Protein Data Bank (RCSB-PDB). The docking mode comparison of the most active compound $\mathbf{7} \mathbf{m}^{\prime}$ and reference drug SAHA in the active site of HDAC2 was demonstrated in Fig. 2. The result suggested that compound $\mathbf{7} \mathbf{m}^{\prime}$ could interact with catalytic pocket and bind similarly to SAHA in the active site of HDAC2. The hydroxamate part of $\mathbf{7} \mathbf{m}^{\prime}$ and SAHA could chelate zinc ion in a similar trigonal bipyramidal fashion, with virtrally identical positioning of the $\mathrm{Zn}^{2+}$ interacting functional groups. Except for metal binding, the generally observed interations of $\mathbf{7} \mathbf{m}^{\prime}$ with HDAC2 involved hydrogen bonds and hydrophobic interations. As illustrated in Fig. 3 for $\mathbf{7} \mathbf{m}^{\prime}$ docked into the enzymatic cavity of HDAC2 via Ligplot program, ${ }^{37)} \mathbf{7} \mathbf{m}^{\prime}$ could form hydrogen bond with amino acid residue His145, His146, Tyr308, His183, Asp181, Phe210 and hydrophobic interactions with Gly154, Phe155, Leu276, Tyr209, Glu208, Gly212. Comparison with the SAHA docking shows that both of them could form similar hydrogen bonds with amino acid residues His145, His146, Tyr308, and similar hydrophobic interactions with Phe155 and Gly154. The Phe155 is a residue in the rim of the active pocket entrance, SAHA and $\mathbf{7} \mathbf{m}^{\prime}$ interacted with Phe155 by phenyl ring and puring ring, respectively, indicating puring as cap domain could increased binding of target compounds with the rim of active pocket similar to the phenyl ring of SAHA.

Antitumor Evaluation With the aim to estimate the potential antiproliferative activity of compounds 7 , we have evaluated their cytotoxicity against two human cancer cell

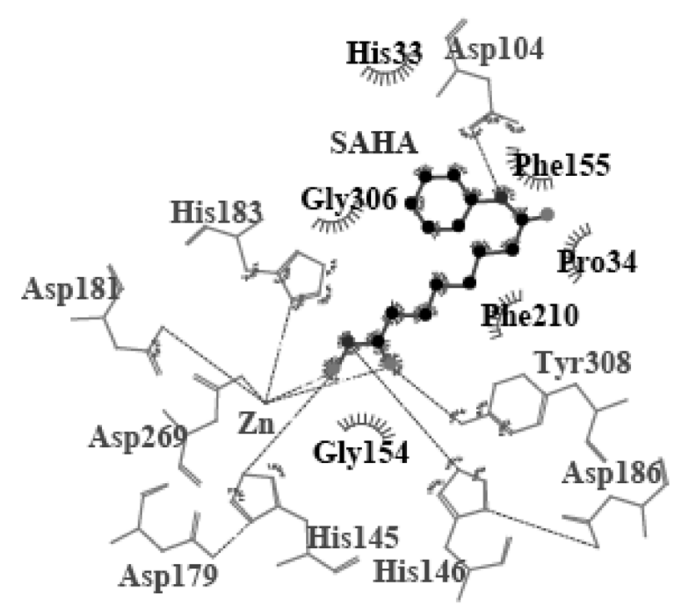

Fig. 3. The 2D Interation Diagrams of $\mathbf{7} \mathbf{m}^{\prime}$ (A) and SAHA (B) with HDAC2 Active Site

The ligands and protein side chains are shown in ball-and-stick representation, the spoked arcs represent protein residues making hydrophobic contacts with the ligand. 
lines, namely HCT116 (colon carcinoma cell line) and K562 (leukemia cancer cell line) by the improved 3-(4,5-dimethylthiahiazol-2-y1)-2,5-diphenytetrazolium bromide (MTT) assay $^{32)}$ and SAHA, PXD101 were used as positive control, results were presented in Table 2. Out of the tested compounds, most of compounds 7, with the only exception of $\mathbf{7} \mathbf{i}^{\prime}$, inhibited HCT116 cells with $\mathrm{IC}_{50}$ values from 0.13 to $62.16 \mu \mathrm{M}$, and $7 \mathbf{b}^{\prime}$,

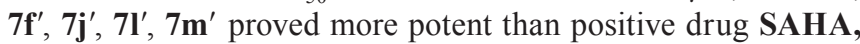
PXD101. Notably, $\mathbf{7} \mathbf{m}^{\prime}$ was the most potent compound against HCT116 cells with an $\mathrm{IC}_{50}$ value of $0.13 \mu \mathrm{M}$. Regarding their activity against K562 cells, twelve compounds $\left(\mathbf{7} \mathbf{e}^{\prime}-\mathbf{7} \mathbf{p}^{\prime}\right)$ showed $\mathrm{IC}_{50}$ values between 1.30 and $40.69 \mu \mathrm{M}$, among them, 7f' $\mathbf{f}^{\prime}, \mathbf{7} \mathbf{l}^{\prime}, \mathbf{7} \mathbf{m}^{\prime}$ proved more potent than positive drug PXD101 with $\mathrm{IC}_{50}$ values of $4.68,5.27,1.30 \mu \mathrm{M}$, respectively. Most of the tested compounds, except for $\mathbf{7} \mathbf{e}^{\prime}, \mathbf{7} \mathbf{h}^{\prime}$ and $\mathbf{7} \mathbf{p}^{\prime}$, exhibited higher activities on HCT116 cells than K562 cells, which may be due to the higher HDACs expression level in HCT116 cells. $^{38)}$ In general, the compounds $\mathbf{7} \mathbf{j}^{\prime}-\mathbf{p}^{\prime}$ with long linker exhibited better anti-proliferative activity than the compounds $7 \mathbf{a}^{\prime}-\mathbf{i}^{\prime}$ with short linker, these findings were consistently with the results of the HDACs inhibition results.

Upregulation Effect of Histone Acetylation Levels To determine whether the target compounds increase histone acetylation levels, compounds $\mathbf{7} \mathbf{m}^{\prime}, \mathbf{7} \mathbf{f}^{\prime}, \mathbf{7} \mathbf{l}^{\prime}, \mathbf{7 o}^{\prime}$ were tested for their effects on histone H3 acetylation levels in HCT116 and K562 cells (Fig. 4), using SAHA as reference compounds. The results showed that at $10 \mu \mathrm{M}$ each of the above compounds could increase the level of acetylated histone H3 in two cell lines, which were similar to the behavior of SAHA. Among four tested compounds, the effect of $\mathbf{7} \mathbf{m}^{\prime}$ on the acetylation degree of histone $\mathrm{H} 3$ was the best, especially the effect of 7m' on HCT116 was higher than that of SAHA. The doesdependencies of $\mathbf{7} \mathbf{m}^{\prime}$ and SAHA on histone acetylation were evaluated (Fig. 5), the results showed that $\mathbf{7} \mathbf{m}^{\prime}$ could increase the amount of acetylated histone H3 in a dose-dependent manner, which is similar to the behavior of SAHA.

Table 2. The Antiproliferative Activities of Compounds

\begin{tabular}{|c|c|c|}
\hline \multirow{2}{*}{ Compounds } & \multicolumn{2}{|c|}{$\mathrm{IC}_{50}(\mu \mathrm{M})$} \\
\hline & HCT116 & K562 \\
\hline $7 \mathbf{a}^{\prime}$ & $7.59 \pm 0.62$ & $111.27 \pm 1.14$ \\
\hline $7 \mathbf{b}^{\prime}$ & $1.07 \pm 0.05$ & $>120$ \\
\hline $7 c^{\prime}$ & $5.52 \pm 1.15$ & $>120$ \\
\hline $7 d^{\prime}$ & $24.05 \pm 5.50$ & $98.34 \pm 0.33$ \\
\hline $7 e^{\prime}$ & $62.16 \pm 7.70$ & $37.53 \pm 2.21$ \\
\hline $7 f^{\prime}$ & $1.25 \pm 0.16$ & $4.68 \pm 0.12$ \\
\hline $7 \mathbf{g}^{\prime}$ & $3.11 \pm 0.41$ & $21.59 \pm 0.12$ \\
\hline $7 \mathbf{h}^{\prime}$ & $20.21 \pm 2.31$ & $20.29 \pm 0.91$ \\
\hline $7 \mathbf{i}^{\prime}$ & $>120$ & $18.07 \pm 0.71$ \\
\hline $7 \mathbf{j}^{\prime}$ & $0.64 \pm 0.03$ & $26.79 \pm 1.01$ \\
\hline $7 \mathbf{k}^{\prime}$ & $3.04 \pm 0.08$ & $40.69 \pm 1.26$ \\
\hline $71^{\prime}$ & $1.39 \pm 0.04$ & $5.27 \pm 0.51$ \\
\hline $7 \mathrm{~m}^{\prime}$ & $0.13 \pm 0.01$ & $1.30 \pm 0.012$ \\
\hline $7 n^{\prime}$ & $10.45 \pm 3.01$ & $12.82 \pm 0.43$ \\
\hline $70^{\prime}$ & $14.45 \pm 1.01$ & $11.58 \pm 0.19$ \\
\hline $7 \mathbf{p}^{\prime}$ & $12.54 \pm 6.92$ & $25.38 \pm 0.88$ \\
\hline SAHA & $1.55 \pm 0.28$ & $0.56 \pm 0.39$ \\
\hline PXD101 & $3.17 \pm 0.60$ & $7.45 \pm 0.52$ \\
\hline
\end{tabular}

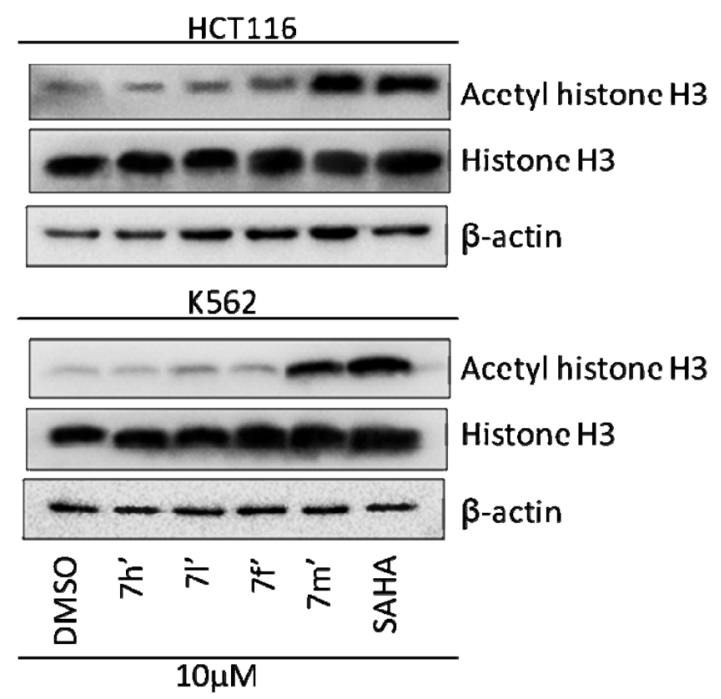

Fig. 4. Effect of Histone H3 Acetylation of $\mathbf{7 m}^{\prime}, \mathbf{7 f}^{\prime}, \mathbf{7 1}^{\prime}, \mathbf{7 0}^{\prime}$ at $10 \mu \mathrm{M}$ in Cultured HCT116 Cancer and K562 Cancer Cells by Western Blotting

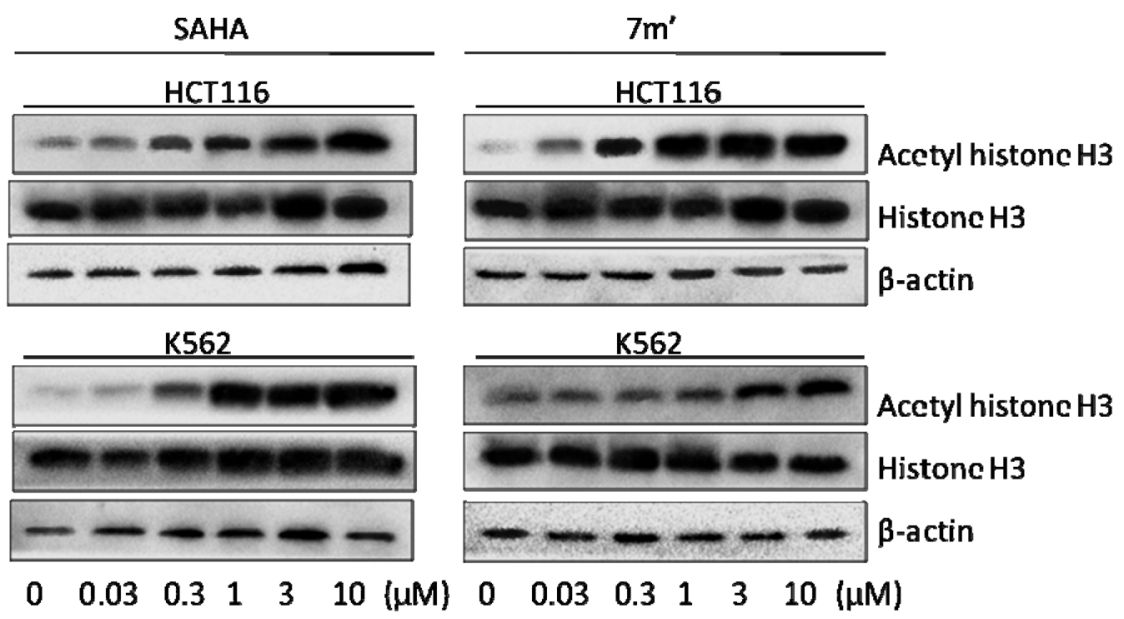

Fig. 5. Effect of Histone H3 Acetylation of $\mathbf{7} \mathbf{m}^{\prime}$, SAHA at Different Concentrations in Cultured HCT116 Cancer and K562 Cancer Cells by Western Blotting 


\section{Conclusion}

The novel hydroxamate derivatives with the purine scaffold were synthesized as HDACs inhibitors and evaluated. Some of the tested compounds exhibited good inhibitory activities

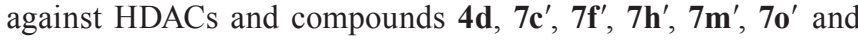
$\mathbf{7} \mathbf{p}^{\prime}$ showed comparable inhibitory activity with SAHA and

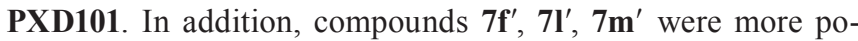
tent than positive drugs SAHA and PXD101 in cellular antiproliferative activity. Molecular docking study indicated that the conformation of $\mathbf{7} \mathbf{m}^{\prime}$ in the active site of HDAC2 was similar to SAHA, which were oriented with the hydroxamic acid towards the catalytic center and formed metal binding with zinc ion. Except for metal binding, the generally observed interations of $\mathbf{7} \mathbf{m}^{\prime}$ with HDAC2 involved hydrogen bonds and hydrophobic interations. Western blot analysis showed each

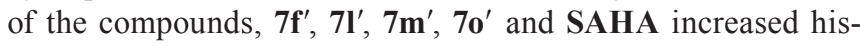
tone $\mathrm{H} 3$ acetylation in HCT116 and K562 cell lines, and $7 \mathbf{m}^{\prime}$ increased the level of acetyl histone $\mathrm{H} 3$ in a dose-dependent manner similar to SAHA.

\section{Experimental}

All starting materials, reagents and solvents were commercially available. All reagents were used without further purification unless stated. IR spectra were measured on $\mathrm{KBr}$ pellets on a Shimadzu FTIR-8000 spectrometer in the range of $4000-400 \mathrm{~cm}^{-1}$. NMR spectra were determined on a Bruker AV $600 \mathrm{MHz}$ spectrometer with $\mathrm{D}_{2} \mathrm{O}$ or dimethyl sulfoxide (DMSO)- $d_{6}$ as the solvent, chemical shift values were reported in parts per million (ppm) and Hertz ( $\mathrm{Hz})$. Mass spectra were recorded on a AB Triple TOF 5600-1 mass spectrometer. Melting points were recorded on an electrothermal melting point apparatus (WRS-1A) and uncorredted.

General Synthetic Method of Compounds $\mathbf{1 a}-\mathbf{1 g}$ and $\mathbf{1 j}$ The starting purin materials $(10 \mathrm{mmol})$ (6-chloro- $9 H$-purin2-amine, 6-chloro-9H-purin, 2,6-dichloro-9H-purin-2-amine) or diamines $(30 \mathrm{mmol})$ were dissolved in $30 \mathrm{~mL}$ anhydrous $n$-butanol, triethylamine (TEA) $(10 \mathrm{mmol})$ was added. The mixture was refluxed for $6 \mathrm{~h}$ under nitrogen atmosphere. The resulting mixture was cooled to room temperature, and concentrated under reduced pressure. The solid was washed with acetone and ethanol to give desired compounds $\mathbf{1 a}-\mathbf{1 g}, \mathbf{1 j}$

$N^{6}$-(2-Aminoethyl)-9H-purine-2,6-diamine (1a, $\left.\mathrm{C}_{7} \mathrm{H}_{11} \mathrm{~N}_{7}\right)$

Light yellow solid; yield $1.7 \mathrm{~g}(88 \%)$; mp: $268-269^{\circ} \mathrm{C}$; ${ }^{1} \mathrm{H}-\mathrm{NMR}\left(600 \mathrm{MHz}, \mathrm{D}_{2} \mathrm{O}\right): \delta=3.02\left(\mathrm{t}, J=5.4 \mathrm{~Hz}, 2 \mathrm{H}, \mathrm{CH}_{2}\right)$, $3.57\left(\mathrm{t}, J=6.0 \mathrm{~Hz}, 2 \mathrm{H}, \mathrm{CH}_{2}\right), 7.72(\mathrm{~s}, 1 \mathrm{H}, \mathrm{CH}) \mathrm{ppm}$.

$N^{6}$-(3-Aminopropyl)-9H-purine-2,6-diamine (1b, $\left.\mathrm{C}_{8} \mathrm{H}_{13} \mathrm{~N}_{7}\right)$

White solid; yield $1.8 \mathrm{~g}$ (89\%); mp: $270-271^{\circ} \mathrm{C}$; ${ }^{1} \mathrm{H}-\mathrm{NMR}$ $\left(600 \mathrm{MHz}, \mathrm{D}_{2} \mathrm{O}\right): \delta=2.01-2.03\left(\mathrm{~m}, 2 \mathrm{H}, \mathrm{CH}_{2}\right), 3.02(\mathrm{t}, J=7.2 \mathrm{~Hz}$, $\left.2 \mathrm{H}, \mathrm{CH}_{2}\right), 3.62\left(\mathrm{~s}, 2 \mathrm{H}, \mathrm{CH}_{2}\right), 8.02(\mathrm{~s}, 1 \mathrm{H}, \mathrm{CH}) \mathrm{ppm}$.

$N^{6}$-(4-Aminobutyl)-9H-purine-2,6-diamine (1c, $\left.\mathrm{C}_{9} \mathrm{H}_{15} \mathrm{~N}_{7}\right)$

White solid; yield $1.7 \mathrm{~g}$ (79\%); mp: $278-279^{\circ} \mathrm{C}$; ${ }^{1} \mathrm{H}-\mathrm{NMR}$ $\left(600 \mathrm{MHz}, \mathrm{D}_{2} \mathrm{O}\right): \delta=1.06\left(\mathrm{~m}, 4 \mathrm{H}, \mathrm{CH}_{2}\right), 3.31-3.32(\mathrm{~m}, 4 \mathrm{H}$, $\left.\mathrm{CH}_{2}\right), 8.01$ (s, $\left.1 \mathrm{H}, \mathrm{CH}\right), 8.95(\mathrm{~s}, 1 \mathrm{H}, \mathrm{NH}) \mathrm{ppm}$.

$N^{6}$-(6-Aminohexyl)-9H-purine-2,6-diamine (1d, $\left.\mathrm{C}_{11} \mathrm{H}_{19} \mathrm{~N}_{7}\right)$

White solid; yield $1.6 \mathrm{~g}$ (66\%); mp: $>300^{\circ} \mathrm{C}$; ${ }^{1} \mathrm{H}-\mathrm{NMR}$ $\left(600 \mathrm{MHz}, \mathrm{D}_{2} \mathrm{O}\right): \delta=1.26-1.27\left(\mathrm{~m}, 4 \mathrm{H}, \mathrm{CH}_{2}\right), 1.50-1.53(\mathrm{~m}$, $\left.4 \mathrm{H}, \mathrm{CH}_{2}\right), 2.83\left(\mathrm{t}, J=7.8 \mathrm{~Hz}, 2 \mathrm{H}, \mathrm{CH}_{2}\right), 3.31\left(\mathrm{~s}, 2 \mathrm{H}, \mathrm{CH}_{2}\right), 7.63$ (s, $1 \mathrm{H}, \mathrm{CH}) \mathrm{ppm}$.

$N^{1}$-(9H-Purine-6-yl)ethane-1,2-diamine (1e, $\left.\mathrm{C}_{7} \mathrm{H}_{10} \mathrm{~N}_{6}\right)$

White solid; yield $1.1 \mathrm{~g}$ (60\%); mp: $>300^{\circ} \mathrm{C}$; ${ }^{1} \mathrm{H}-\mathrm{NMR}$ $\left(600 \mathrm{MHz}, \mathrm{D}_{2} \mathrm{O}\right) \delta=3.27\left(\mathrm{t}, J=6.0 \mathrm{~Hz}, 2 \mathrm{H}, \mathrm{CH}_{2}\right), 3.84$ (t,
$\left.J=6.0 \mathrm{~Hz}, 2 \mathrm{H}, \mathrm{CH}_{2}\right), 8.07(\mathrm{~s}, 1 \mathrm{H}, \mathrm{CH}), 8.17(\mathrm{~s}, 1 \mathrm{H}, \mathrm{CH}) \mathrm{ppm}$. $N^{1}$-(9H-Purin-6-yl)butane-1,4-diamine (1f, $\left.\mathrm{C}_{9} \mathrm{H}_{14} \mathrm{~N}_{6}\right)$

White solid; yield $1.4 \mathrm{~g}$ (70\%); mp: $>300^{\circ} \mathrm{C}$; ${ }^{1} \mathrm{H}-\mathrm{NMR}$ $\left(600 \mathrm{MHz}, \mathrm{D}_{2} \mathrm{O}\right) \delta=1.83-1.85\left(\mathrm{~m}, 4 \mathrm{H}, \mathrm{CH}_{2}\right), 3.01(\mathrm{t}, J=6.0 \mathrm{~Hz}$, $\left.2 \mathrm{H}, \mathrm{CH}_{2}\right), 3.77\left(\mathrm{~s}, 2 \mathrm{H}, \mathrm{CH}_{2}\right), 8.40(\mathrm{~s}, 1 \mathrm{H}, \mathrm{CH}), 8.54(\mathrm{~s}, 1 \mathrm{H}$, $\mathrm{CH}) \mathrm{ppm}$.

$N^{1}$-(2-Chloro-9H-purin-6-yl)ethane-1,2-diamine (1g, $\left.\mathrm{C}_{7} \mathrm{H}_{9} \mathrm{ClN}_{6}\right)$

White solid; yield $1.3 \mathrm{~g}(62 \%)$; mp: $198-200^{\circ} \mathrm{C}$; ${ }^{1} \mathrm{H}-\mathrm{NMR}$ $\left(600 \mathrm{MHz}, \mathrm{D}_{2} \mathrm{O}\right) \delta=2.51\left(\mathrm{t}, J=6.6 \mathrm{~Hz}, 2 \mathrm{H}, \mathrm{CH}_{2}\right), 2.87(\mathrm{~d}$, $\left.J=4.8 \mathrm{~Hz}, 2 \mathrm{H}, \mathrm{CH}_{2}\right), 3.53$ (s, 2H, $\left.\mathrm{NH}_{2}\right), 8.13$ (s, $\left.1 \mathrm{H}, \mathrm{CH}\right), 8.23$ (s, 1H, NH) ppm;

$N^{1}$-(2-Chloro-9H-purin-6-yl)propane-1,3-diamine (1j, $\mathrm{C}_{8} \mathrm{H}_{11} \mathrm{ClN}_{6}$ )

White solid; yield $1.9 \mathrm{~g}$ (82\%); mp: $210-212^{\circ} \mathrm{C}$; ${ }^{1} \mathrm{H}-\mathrm{NMR}$ $\left(600 \mathrm{MHz}, \mathrm{D}_{2} \mathrm{O}\right) \delta=1.96\left(\mathrm{t}, J=7.2 \mathrm{~Hz}, 2 \mathrm{H}, \mathrm{CH}_{2}\right), 2.19-3.01(\mathrm{~m}$, $\left.2 \mathrm{H}, \mathrm{CH}_{2}\right), 3.56\left(\mathrm{~s}, J=6.6 \mathrm{~Hz}, 2 \mathrm{H}, \mathrm{CH}_{2}\right), 7.92(\mathrm{~s}, 1 \mathrm{H}, \mathrm{CH}) \mathrm{ppm}$.

General Synthetic Method of Compounds 2g-2l The intermediate $\mathbf{1 g}$ or $\mathbf{1 j}(10 \mathrm{mmol})$ was dissolved in $20 \mathrm{~mL}$ anhydrous $n$-butanol, then catalytic amount of TFA ( $1 \mathrm{mmol})$ was added, and then aromatic amine $(20 \mathrm{mmol})$ was dropped into the solution. The mixture was stirred for $12 \mathrm{~h}$ at $120^{\circ} \mathrm{C}$. The resulting mixture was cooled to room temperature, filtered and the solid was washed with ether and ethanol to give compounds $\mathbf{2 g - 2 1}$.

$N^{6}$-(2-Aminoethyl)- $N^{2}$-phenyl-9H-purine-2,6-diamine

$(2 \mathrm{~g}$ $\mathrm{C}_{13} \mathrm{H}_{15} \mathrm{~N}_{7}$ )

White solid; yield $2.0 \mathrm{~g}$ (75\%); mp: $231-234^{\circ} \mathrm{C}$; ${ }^{1} \mathrm{H}-\mathrm{NMR}$ $\left(600 \mathrm{MHz}, \mathrm{DMSO}-d_{6}\right) \delta=3.12\left(\mathrm{t}, J=6.6 \mathrm{~Hz}, 2 \mathrm{H}, \mathrm{CH}_{2}\right), 3.68$ (t, J=6.6 Hz, 2H, $\left.\mathrm{CH}_{2}\right), 7.08(\mathrm{~s}, 1 \mathrm{H}, \mathrm{CH}), 7.28(\mathrm{~d}, J=7.8 \mathrm{~Hz}$, 2H, ArH), 7.33-7.35 (m, 2H, ArH), 7.86 (s, 1H, ArH) ppm; ${ }^{13} \mathrm{C}-\mathrm{NMR}\left(151 \mathrm{MHz}, \mathrm{DMSO}-d_{6}\right) \delta=20.30,36.37,115.79,117.76$, $119.11,128.94,129.85,152.58,158.51,158.72$ ppm; high resolution (HR)-MS-electrospray ionization (ESI): $m / z=270.1389$ $\left([\mathrm{M}+\mathrm{H}]^{+}\right.$, Calcd), 270.1382 (Found).

$N^{6}$-(2-Aminoethyl)- $N^{2}$-(4-methylphenyl)-9H-purine-2,6diamine $\left(\mathbf{2} \mathbf{h}, \mathrm{C}_{14} \mathrm{H}_{17} \mathrm{~N}_{7}\right)$

White solid; yield $2.2 \mathrm{~g}$ (77\%); mp: $215-217^{\circ} \mathrm{C}$; ${ }^{1} \mathrm{H}-\mathrm{NMR}$ $\left(600 \mathrm{MHz}, \mathrm{DMSO}-d_{6}\right) \delta=2.15\left(\mathrm{q}, J=6.6 \mathrm{~Hz}, 3 \mathrm{H}, \mathrm{CH}_{3}\right), 2.12$ (t, J=6.6 Hz, 2H, $\mathrm{CH}_{2}$ ), 3.65 (q, J=7.6 Hz, 2H, $\mathrm{CH}_{2}$ ), 7.02 $(\mathrm{d}, J=7.2 \mathrm{~Hz}, 2 \mathrm{H}, \mathrm{ArH}), 7.16(\mathrm{~d}, J=7.8 \mathrm{~Hz}, 2 \mathrm{H}, \mathrm{ArH}), 7.90$ (s, H, ArH) ppm; ${ }^{13} \mathrm{C}-\mathrm{NMR}\left(151 \mathrm{MHz}, \mathrm{DMSO}-d_{6}\right) \delta=20.30$, 39.10, 115.79, 117.76, 131.11, 132.31, 133.71, 152.58, 158.51, 167.49 ppm; HR-MS-ESI: $m / z=284.1615\left([\mathrm{M}+\mathrm{H}]^{+}, \mathrm{Calcd}\right)$, 284.1625 (Found) .

$N^{6}$-(2-Aminoethyl)- $N^{2}$-(4-hydroxyphenyl)-9H-purine-2,6diamine (2i, $\mathrm{C}_{13} \mathrm{H}_{15} \mathrm{~N}_{7} \mathrm{O}$ )

White solid; yield $2.1 \mathrm{~g}$ (75\%); mp: $201-204^{\circ} \mathrm{C}$; ${ }^{1} \mathrm{H}-\mathrm{NMR}$ $\left(600 \mathrm{MHz}, \mathrm{DMSO}-d_{6}\right) \delta=3.11\left(\mathrm{t}, J=7.2 \mathrm{~Hz}, 2 \mathrm{H}, \mathrm{CH}_{2}\right), 3.64$ (q, $\left.J=6.6 \mathrm{~Hz}, 2 \mathrm{H}, \mathrm{CH}_{2}\right), 6.70(\mathrm{~d}, J=7.8 \mathrm{~Hz}, 2 \mathrm{H}, \mathrm{ArH}), 7.11-7.13$ (m, 2H, ArH), 7.79 (s, H, ArH) ppm; ${ }^{13} \mathrm{C}-\mathrm{NMR}(151 \mathrm{MHz}$, DMSO- $\left.d_{6}\right) \quad \delta=21.30,39.37,123.59,125.11,125.71,128.94$, 131.85, 132.58, 145.52, 148.72 ppm; HR-MS-ESI: $m / z=286.1416$ $\left([\mathrm{M}+\mathrm{H}]^{+}\right.$, Calcd). Found (286.1413).

$N^{6}$-(3-Aminopropyl)- $N^{2}$-(4-methyl-phenyl)-9H-purine-2,6diamine $\left(2 \mathbf{j}, \mathrm{C}_{15} \mathrm{H}_{19} \mathrm{~N}_{7}\right)$

White solid; yield $2.6 \mathrm{~g}(86 \%)$; mp: $245-247^{\circ} \mathrm{C}$; ${ }^{1} \mathrm{H}-\mathrm{NMR}$ $\left(600 \mathrm{MHz}, \mathrm{DMSO}-d_{6}\right) \delta=1.84\left(\mathrm{t}, J=6.6 \mathrm{~Hz}, 3 \mathrm{H}, \mathrm{CH}_{3}\right), 2.83$ (q, $\left.J=7.2 \mathrm{~Hz}, 2 \mathrm{H}, \mathrm{CH}_{2}\right), 2.98\left(\mathrm{t}, J=7.2 \mathrm{~Hz}, 2 \mathrm{H}, \mathrm{CH}_{2}\right), 3.47-3.49$ $\left(\mathrm{m}, 2 \mathrm{H}, \mathrm{CH}_{2}\right), 7.08$ (d, J=7.8 Hz, 2H, ArH), 7.18-7.21 (m, 2H, $\mathrm{ArH}), 7.84$ (s, H, ArH) ppm; ${ }^{13} \mathrm{C}-\mathrm{NMR}$ (151 MHz, DMSO$\left.d_{6}\right) \quad \delta=20.30,39.80,39.90,117.23,119.74,131.15,131.16$, $132.24,132.51,150.25,154.51,165.43$ ppm; HR-MS-ESI: 
$m / z=298.1702\left([\mathrm{M}+\mathrm{H}]^{+}\right.$, Calcd), 298.1709 (Found).

$N^{6}$-(3-Aminopropyl)- $N^{2}$-(4-hydroxyphenyl)-9H-purine-2,6diamine $\left(\mathbf{2} \mathbf{k}, \mathrm{C}_{14} \mathrm{H}_{17} \mathrm{~N}_{7} \mathrm{O}\right)$

White solid; yield $2.6 \mathrm{~g}$ (87\%); mp: $237-239^{\circ} \mathrm{C}$; ${ }^{1} \mathrm{H}-\mathrm{NMR}$ $\left(600 \mathrm{MHz}, \mathrm{DMSO}-d_{6}\right) \delta=1.87\left(\mathrm{t}, J=6.6 \mathrm{~Hz}, 2 \mathrm{H}, \mathrm{CH}_{2}\right), 2.87$ (t, $\left.J=7.2 \mathrm{~Hz}, 2 \mathrm{H}, \mathrm{CH}_{2}\right), 3.51\left(\mathrm{t}, J=6.6 \mathrm{~Hz}, 2 \mathrm{H}, \mathrm{CH}_{2}\right), 7.10(\mathrm{~d}$, $J=9.5 \mathrm{~Hz}, 2 \mathrm{H}, \mathrm{ArH}), 7.22$ (q, $J=8.4 \mathrm{~Hz}, 2 \mathrm{H}, \mathrm{ArH}), 7.77$ (s, 1H, CH) ppm; ${ }^{13} \mathrm{C}-\mathrm{NMR}\left(151 \mathrm{MHz}, \mathrm{DMSO}-d_{6}\right) \quad \delta=37.21,39.59$, 39.98, 115.39, 116.54, 116.66, 118.64, 121.89, 124.13, 157.00, 157.04 ppm; HR-MS-ESI: $m / z=300.1495\left([\mathrm{M}+\mathrm{H}]^{+}, \mathrm{Calcd}\right)$, 300.1488 (Found).

$N^{6}$-(3-Aminopropyl)- $N^{2}$-(4-methoxyphenyl)-9H-purine-2,6diamine (2l, $\mathrm{C}_{15} \mathrm{H}_{19} \mathrm{~N}_{7} \mathrm{O}$ )

White solid; yield $2.4 \mathrm{~g}$ (76\%); mp: $199-202^{\circ} \mathrm{C}$; ${ }^{1} \mathrm{H}-\mathrm{NMR}$ $\left(600 \mathrm{MHz}, \mathrm{D}_{2} \mathrm{O}\right) \delta=1.90\left(\mathrm{t}, J=6.6 \mathrm{~Hz}, 2 \mathrm{H}, \mathrm{CH}_{2}\right), 1.96-1.99(\mathrm{~m}$, $\left.2 \mathrm{H}, \mathrm{CH}_{2}\right), 2.90\left(\mathrm{t}, J=7.2 \mathrm{~Hz}, 2 \mathrm{H}, \mathrm{CH}_{2}\right), 3.53\left(\mathrm{~s}, 2 \mathrm{H}, \mathrm{NH}_{2}\right), 3.75$ $\left(\mathrm{s}, 3 \mathrm{H}, \mathrm{CH}_{3}\right), 6.90(\mathrm{~d}, J=9.0 \mathrm{~Hz}, 2 \mathrm{H}, \mathrm{ArH}), 7.30(\mathrm{~d}, J=9.0 \mathrm{~Hz}$, 2H, ArH), 7.84 (s, 1H, CH) ppm; ${ }^{13} \mathrm{C}-\mathrm{NMR}(151 \mathrm{MHz}, \mathrm{DMSO}-$ $\left.d_{6}\right) \delta=15.05,19.80,20.23,35.94,118.92,119.76,128.11,128.58$, 129.41, 139.23, 141.75, 156.22, 161.51,178.66 ppm; HR-MS-ESI: $m / z=314.1651\left([\mathrm{M}+\mathrm{H}]^{+}\right.$, Calcd), 314.1665 (Found).

General Synthetic Method of Compounds 3a-3l Compounds 1a-1f or $\mathbf{2 g - 2 l}(5 \mathrm{mmol})$ was dissolved by $10 \mathrm{~cm}^{3}$ $\mathrm{H}_{2} \mathrm{O}$ and $15 \mathrm{~cm}^{3}$ acetonitrile, respectively, and then $\mathrm{NaHCO}_{3}$ $(5 \mathrm{mmol})$ was added, the solution was stirred at $0^{\circ} \mathrm{C}$, 4-nitrophenyl chloroformate $(5 \mathrm{mmol})$ pre-dissolved with acetonitrile was dropped into the solution. The mixture was stirred for $0.5-1 \mathrm{~h}$ at $0^{\circ} \mathrm{C}$. Because of aftertreatments of $\mathbf{3 a}-\mathbf{3 f}$ were difficult, they were concentrated and then directly used for synthesizing $\mathbf{4 a}-\mathbf{4 l}$ without further purification. The resulting precipitations of $\mathbf{3 g}-\mathbf{3 l}$ were filtered and then washed with acetonitrile to give compounds $\mathbf{3 g}-\mathbf{3 l}$.

4-Nitrophenyl(2-(2-(phenylamino)-9H-purin-6-yl)amino)ethyl)carbamate $\left(3 g, \mathrm{C}_{20} \mathrm{H}_{18} \mathrm{~N}_{8} \mathrm{O}_{4}\right)$

White solid; yield $1.6 \mathrm{~g}$ (73\%); mp: $214-216^{\circ} \mathrm{C}$; IR $(\mathrm{KBr})$ : $v=1658$ (CO-acetyl), 2901 (CH-aliph), 3009 (CH-aryl), 3424 (NH) $\mathrm{cm}^{-1}$.

4-Nitrophenyl(2-(2-(4-methylphenyl)amino)-9H-purin-6yl)amino)ethyl) carbamate $\left(\mathbf{3 h}, \mathrm{C}_{21} \mathrm{H}_{20} \mathrm{~N}_{8} \mathrm{O}_{4}\right)$

White solid; yield $1.5 \mathrm{~g}(68 \%)$; mp: $225-226^{\circ} \mathrm{C}$; IR (KBr): $v=1648$ (CO-acetyl), 2941 (CH-aliph), 3029 (CH-aryl), 3404 (NH) $\mathrm{cm}^{-1}$.

4-Nitrophenyl(2-(2-((4-hydroxyphenyl)amino)-9H-purin-6yl)amino)ethyl)carbamate $\left(3 \mathbf{i}, \mathrm{C}_{20} \mathrm{H}_{18} \mathrm{~N}_{8} \mathrm{O}_{5}\right)$

White solid; yield $1.7 \mathrm{~g}$ (75\%); mp: $225-228^{\circ} \mathrm{C}$; IR ( $\left.\mathrm{KBr}\right)$ : $v=1685$ (CO-acetyl), 2981 (CH-aliph), 3049 (CH-aryl), 3435 (NH) $\mathrm{cm}^{-1}$.

4-Nitrophenyl(3-(2-(4-methylphenyl)amino)-9H-purin-6-yl)amino)propyl)carbamate $\left(3 \mathbf{j}, \mathrm{C}_{22} \mathrm{H}_{22} \mathrm{~N}_{8} \mathrm{O}_{4}\right)$

White solid; yield $1.5 \mathrm{~g}$ (64\%); mp: $187-190^{\circ} \mathrm{C}$; IR (KBr): $v=1645$ (CO-acetyl), 2981 (CH-aliph), 3049 (CH-aryl), 3415 (NH) $\mathrm{cm}^{-1}$.

4-Nitrophenyl(3-(2-((4-hydroxyphenyl)amino)-9H-purin-6yl)amino)propyl)carbamate (3k, $\mathrm{C}_{21} \mathrm{H}_{20} \mathrm{~N}_{8} \mathrm{O}_{5}$ )

White solid; yield $1.2 \mathrm{~g}$ (72\%); mp: $198-199^{\circ} \mathrm{C}$; IR (KBr): $v=1635$ (CO-acetyl), 2881 (CH-aliph), 3002 (CH-aryl), 3359 (NH) $\mathrm{cm}^{-1}$.

4-Nitrophenyl(3-(2-((4-methoxyphenyl)amino)-9H-purin-6yl)amino)propyl)carbamate $\left(\mathbf{3 l}, \mathrm{C}_{22} \mathrm{H}_{22} \mathrm{~N}_{8} \mathrm{O}_{5}\right)$

White solid; yield $1.6 \mathrm{~g}$ (65\%); mp: $192-194^{\circ} \mathrm{C}$; IR (KBr): $v=1675$ (CO-acetyl), 2920 (CH-aliph), 3007 (CH-aryl), 3410
(NH) $\mathrm{cm}^{-1}$.

General Synthetic Method of Compounds 4a-4l At room temperature, to a solution of hydroxylamine hydrochloride $(5 \mathrm{mmol})$ in $10 \mathrm{~mL}$ anhydrous methanol, $\mathrm{NaOH}(10 \mathrm{mmol})$ was added. After stirring the mixture at room temperature for $30 \mathrm{~min}$, adding it to the previous $\mathbf{3}$, and the mixture was stirred for $5 \mathrm{~h}$ at $60^{\circ} \mathrm{C}$. Then most of the methanol was evaporated and the residues were adjusted to $\mathrm{pH}$ 5-6 with $\mathrm{HCl}(1 \mathrm{~mol} / \mathrm{L})$. The solution was concentrated under reduced pressure and the crude product was purified by chromatography on a silica gel column (methanol/dichloromethane, $1: 3$ ) to give desired compounds $\mathbf{4 a}-\mathbf{4 l}$.

1-(2-(2-Amino-9H-purin-6-yl)amino)ethyl)-3-hydroxyurea (4a, $\mathrm{C}_{8} \mathrm{H}_{12} \mathrm{~N}_{8} \mathrm{O}_{2}$ )

Isolated yield: $42 \%$; white powder; mp: $185-187^{\circ} \mathrm{C}$; IR (KBr): $v=1603$ (CO-acetyl), 2949 (CH-aliph), 3070 (CH-aryl), 3200-3500 (br $\left.\mathrm{NH}_{2}, \mathrm{NH}, \mathrm{OH}\right) \mathrm{cm}^{-1}$; ${ }^{1} \mathrm{H}-\mathrm{NMR}(600 \mathrm{MHz}$, DMSO- $\left.d_{6}\right) \delta=3.13\left(\mathrm{t}, J=5.4 \mathrm{~Hz}, 2 \mathrm{H}, \mathrm{CH}_{2}\right), 3.16(\mathrm{t}, J=5.4 \mathrm{~Hz}$, $\left.2 \mathrm{H}, \mathrm{CH}_{2}\right), 4.16\left(\mathrm{~s}, 2 \mathrm{H}, \mathrm{NH}_{2}\right), 6.82(\mathrm{~s}, 2 \mathrm{H}, \mathrm{NH}), 8.31(\mathrm{~s}, 1 \mathrm{H}$, $\mathrm{CH}), 8.61(\mathrm{~s}, 1 \mathrm{H}, \mathrm{NH}) \mathrm{ppm} ;{ }^{13} \mathrm{C}-\mathrm{NMR}\left(151 \mathrm{MHz}, \mathrm{DMSO}-d_{6}\right)$ $\delta=27.9,56.5,86.8,101.9,116.8,139.0,147.0,154.7,162.0 \mathrm{ppm}$; HR-MS-ESI: $\quad m / z=253.1161 \quad\left([\mathrm{M}+\mathrm{H}]^{+}, \quad\right.$ Calcd $), 253.1164$ (Found).

1-(3-(2-Amino-9H-purin-6-yl)amino)propyl)-3-hydroxyurea (4b, $\mathrm{C}_{9} \mathrm{H}_{14} \mathrm{~N}_{8} \mathrm{O}_{2}$ )

Isolated yield: 52\%; white powder; mp: $190-193^{\circ} \mathrm{C}$; IR (KBr): $v=1601$ (CO-acetyl), 2908 (CH-aliph), 3057 (CH-aryl), 3200-3500 (br. $\left.\mathrm{NH}_{2}, \mathrm{NH}, \mathrm{OH}\right) \mathrm{cm}^{-1}$; ${ }^{1} \mathrm{H}-\mathrm{NMR}(600 \mathrm{MHz}$, DMSO- $\left.d_{6}\right) \delta=1.63\left(\mathrm{t}, J=5.4 \mathrm{~Hz}, 2 \mathrm{H}, \mathrm{CH}_{2}\right), 2.81(\mathrm{t}, J=6.6 \mathrm{~Hz}$, $\left.2 \mathrm{H}, \mathrm{CH}_{2}\right), 3.09\left(\mathrm{t}, \mathrm{J}=6.0 \mathrm{~Hz}, 2 \mathrm{H}, \mathrm{CH}_{2}\right), 5.66\left(\mathrm{~s}, 2 \mathrm{H}, \mathrm{NH}_{2}\right), 7.08$ (s, 1H, NH), $7.21(\mathrm{~s}, 1 \mathrm{H}, \mathrm{NH}), 7.63(\mathrm{~s}, 1 \mathrm{H}, \mathrm{NH}), 8.31(\mathrm{~s}, 1 \mathrm{H}$, $\mathrm{CH}), 8.71(\mathrm{~s}, 1 \mathrm{H}, \mathrm{NH}) \mathrm{ppm} ;{ }^{13} \mathrm{C}-\mathrm{NMR}\left(151 \mathrm{MHz}, \mathrm{DMSO}-d_{6}\right)$ $\delta=26.5,26.6,73.2,90.5,131.1,136.4,148.6,156.7,162.0 \mathrm{ppm}$; HR-MS-ESI: $\quad m / z=267.1318 \quad\left([\mathrm{M}+\mathrm{H}]^{+}, \quad\right.$ Calcd $), \quad 267.1312$ (Found).

1-(4-(2-Amino-9H-purin-6-yl)amino)butyl)-3-hydroxyurea (4c, $\mathrm{C}_{10} \mathrm{H}_{16} \mathrm{~N}_{8} \mathrm{O}_{2}$ )

Isolated yield: $51 \%$; white powder; mp: $195-198^{\circ} \mathrm{C}$; IR (KBr): $v=1614$ (CO-acetyl), 2845 (CH-aliph), 3097 (CH-aryl), 3200-3500 (br. $\left.\mathrm{NH}_{2}, \mathrm{NH}, \mathrm{OH}\right) \mathrm{cm}^{-1}$; ${ }^{1} \mathrm{H}-\mathrm{NMR}(600 \mathrm{MHz}$, DMSO- $\left.d_{6}\right) \delta=1.48-1.56\left(\mathrm{~m}, 4 \mathrm{H}, \mathrm{CH}_{2}\right), 3.07(\mathrm{t}, J=6.0 \mathrm{~Hz}, 2 \mathrm{H}$, $\left.\mathrm{CH}_{2}\right), 3.09$ (s, 2H, $\left.\mathrm{CH}_{2}\right), 4.01\left(\mathrm{~s}, 2 \mathrm{H}, \mathrm{NH}_{2}\right), 6.70(\mathrm{~s}, 2 \mathrm{H}, \mathrm{NH})$, $8.21(\mathrm{~s}, 1 \mathrm{H}, \mathrm{CH}), 8.51(\mathrm{~s}, 1 \mathrm{H}, \mathrm{NH}) \mathrm{ppm} ;{ }^{13} \mathrm{C}-\mathrm{NMR}(151 \mathrm{MHz}$, DMSO- $\left.d_{6}\right) \delta=26.1,27.6,29.8,118.8,41.7,149.9,153.6,156.0$, $168.6 \mathrm{ppm} ;$ HR-MS-ESI: $m / z=281.1474\left([\mathrm{M}+\mathrm{H}]^{+}, \quad\right.$ Calcd $)$, 281.1463 (Found).

1-(6-(2-Amino-9H-purin-6-yl)amino)hexyl)-3-hydroxyurea (4d, $\mathrm{C}_{12} \mathrm{H}_{20} \mathrm{~N}_{8} \mathrm{O}_{2}$ )

Isolated yield: $37 \%$; white powder; $\mathrm{mp}: 170-172^{\circ} \mathrm{C}$; IR (KBr): $v=1620$ (CO-acetyl), 2943 (CH-aliph), 3057 (CH-aryl), 3200-3500 (br. $\left.\mathrm{NH}_{2}, \mathrm{NH}, \mathrm{OH}\right) \mathrm{cm}^{-1}$; ${ }^{1} \mathrm{H}-\mathrm{NMR}(600 \mathrm{MHz}$, DMSO- $\left.d_{6}\right) \delta=1.27-1.33\left(\mathrm{~m}, 4 \mathrm{H}, \mathrm{CH}_{2}\right), 1.42(\mathrm{t}, J=7.2 \mathrm{~Hz}, 2 \mathrm{H}$, $\left.\mathrm{CH}_{2}\right), 1.58\left(\mathrm{t}, J=7.2 \mathrm{~Hz}, 2 \mathrm{H}, \mathrm{CH}_{2}\right), 3.04(\mathrm{q}, J=6.6 \mathrm{~Hz}, 2 \mathrm{H}$, $\mathrm{CH}_{2}$ ), 3.32 (s, 2H, $\left.\mathrm{CH}_{2}\right), 3.44\left(\mathrm{~s}, 2 \mathrm{H}, \mathrm{NH}_{2}\right), 6.65$ (t, $J=6.0 \mathrm{~Hz}$, 2H, NH), 7.89 (s, 1H, NH), $8.20(\mathrm{~s}, 1 \mathrm{H}, \mathrm{CH}), 8.50(\mathrm{~s}, 1 \mathrm{H}$, $\mathrm{NH}), 12.66$ (s, $1 \mathrm{H}, \mathrm{OH}) \mathrm{ppm} ;{ }^{13} \mathrm{C}-\mathrm{NMR}\left(151 \mathrm{MHz}, \mathrm{DMSO}-d_{6}\right)$ $\delta=26.0,27.7,29.8,118.9,141.7,150.0,153.7,156.0,168.6 \mathrm{ppm}$; HR-MS-ESI: $\quad m / z=309.1787 \quad\left([\mathrm{M}+\mathrm{H}]^{+}, \quad\right.$ Calcd $), \quad 309.1773$ (Found).

1-(2-(9H-Purin-6-yl)amino)ethyl)-3-hydroxyurea $\left(4 \mathrm{e}, \mathrm{C}_{8} \mathrm{H}_{11} \mathrm{~N}_{7} \mathrm{O}_{2}\right)$ Isolated yield: $50 \%$; white powder; mp: $185-186^{\circ} \mathrm{C}$; IR 
(KBr): $v=1612$ (CO-acetyl), 2999 (CH-aliph), 3057 (CH-aryl), $3255(\mathrm{NH}), 3443(\mathrm{OH}) \mathrm{cm}^{-1}$; ${ }^{1} \mathrm{H}-\mathrm{NMR}\left(600 \mathrm{MHz}, \mathrm{DMSO}-d_{6}\right)$ $\delta=3.35$ ( $\left.\mathrm{t}, J=7.2 \mathrm{~Hz}, 2 \mathrm{H}, \mathrm{CH}_{2}\right), 3.73\left(\mathrm{q}, J=7.8 \mathrm{~Hz}, 2 \mathrm{H}, \mathrm{CH}_{2}\right.$ ), $7.60(\mathrm{~s}, 1 \mathrm{H}, \mathrm{CH}), 8.90(\mathrm{~s}, 1 \mathrm{H}, \mathrm{CH}), 9.86(\mathrm{~s}, 1 \mathrm{H}, \mathrm{NH}) \mathrm{ppm}$; ${ }^{13} \mathrm{C}-\mathrm{NMR}\left(151 \mathrm{MHz}, \mathrm{DMSO}-d_{6}\right) \delta=25.4,31.2,42.9,49.1,115.4$, $119.9,123.5,131.5,141.7,149.9,152.9,153.7,174.1$ ppm; HRMS-ESI: $m / z=238.1052\left([\mathrm{M}+\mathrm{H}]^{+}\right.$, Calcd), 238.1041 (Found).

1-(4-(9H-Purin-6-yl)amino)butyl)-3-hydroxyurea (4f, $\left.\mathrm{C}_{10} \mathrm{H}_{15} \mathrm{~N}_{7} \mathrm{O}_{2}\right)$ Isolated yield: $45 \%$; white powder; $\mathrm{mp}$ : $195-196^{\circ} \mathrm{C}$; IR (KBr): $v=1688$ (CO-acetyl), 2979 (CH-aliph), 3255 (NH), 3413 $(\mathrm{OH}) \mathrm{cm}^{-1} ;{ }^{1} \mathrm{H}-\mathrm{NMR}\left(600 \mathrm{MHz}, \mathrm{DMSO}-d_{6}\right) \delta=1.45-1.48(\mathrm{~m}$, $2 \mathrm{H}, \mathrm{CH}_{2}$ ) 1.58 (t, $J=7.2 \mathrm{~Hz}, 2 \mathrm{H}, \mathrm{CH}_{2}$ ), 3.04 (q, $J=7.2 \mathrm{~Hz}, 2 \mathrm{H}$, $\left.\mathrm{CH}_{2}\right), 3.46\left(\mathrm{q}, J=7.2 \mathrm{~Hz}, 2 \mathrm{H}, \mathrm{CH}_{2}\right), 6.73(\mathrm{t}, J=6.0 \mathrm{~Hz}, 1 \mathrm{H}, \mathrm{NH})$, 7.65 (s, 1H, CH), 8.09 (s, 1H, CH), 8.12 (t, J=9.6 Hz, 1H, NH), $8.24(\mathrm{~s}, 1 \mathrm{H}, \mathrm{NH}), 8.54(\mathrm{t}, J=5.4 \mathrm{~Hz}, 1 \mathrm{H}, \mathrm{NH}), 12.89$ (s, $1 \mathrm{H}$, OH) ppm; ${ }^{13} \mathrm{C}-\mathrm{NMR}\left(151 \mathrm{MHz}, \mathrm{DMSO}-d_{6}\right) \delta=24.9,26.3,28.6$, 28.9, 29.7, 34.2, 43.7, 49.1, 115.5, 118.9, 124.0, 130.6, 142.3, 151.0, 153.2, 154.4, 175.0 ppm; HR-MS-ESI: $m / z=266.1365$ $\left([\mathrm{M}+\mathrm{H}]^{+}\right.$, Calcd), 266.1378 (Found).

1-(2-(2-(Phenylamino)-9H-purin-6-yl)amino)ethyl)-3hydroxyurea $\left(4 \mathrm{~g}, \mathrm{C}_{14} \mathrm{H}_{16} \mathrm{~N}_{8} \mathrm{O}_{2}\right)$

Isolated yield: $32 \%$; white powder; $\mathrm{mp}$ : $179-182^{\circ} \mathrm{C}$; IR (KBr): $v=1610$ (CO-acetyl), 2855 (CH-aliph), 3000-3400 (br. $\mathrm{CH}$-aryl, NH, OH) cm ${ }^{-1} ;{ }^{1} \mathrm{H}-\mathrm{NMR}\left(600 \mathrm{MHz}, \mathrm{D}_{2} \mathrm{O}\right) \delta=3.16(\mathrm{t}$, $\left.J=6.6 \mathrm{~Hz}, 2 \mathrm{H}, \mathrm{CH}_{2}\right), 3.37\left(\mathrm{t}, J=6.6 \mathrm{~Hz}, 2 \mathrm{H}, \mathrm{CH}_{2}\right), 4.18(\mathrm{~s}, 1 \mathrm{H}$, $\mathrm{NH}), 6.82(\mathrm{~s}, 1 \mathrm{H}, \mathrm{NH}), 7.20(\mathrm{~s}, 2 \mathrm{H}, \mathrm{ArH}), 7.30$ (d, $J=7.6 \mathrm{~Hz}$, 1H, ArH), $7.82(\mathrm{~d}, J=7.1 \mathrm{~Hz}, 1 \mathrm{H}, \mathrm{ArH}), 8.00(\mathrm{~s}, 1 \mathrm{H}, \mathrm{CH})$ ppm $;{ }^{13} \mathrm{C}-\mathrm{NMR}\left(151 \mathrm{MHz}, \mathrm{DMSO}-d_{6}\right) \delta=21.32,39.59,76.10$, 115.79 , 119.76, 129.14, 129.28, 129.65, 129.84, 131.16, 137.99, 139.05 ppm; HR-MS-ESI: $m / z=329.1474\left([\mathrm{M}+\mathrm{H}]^{+}\right.$, Calcd $)$, 329.1478 (Found).

1-(2-(2-(4-Methyl-phenyl)amino)-9H-purin-6-yl)amino)ethyl)-3-hydroxyurea (4h, $\mathrm{C}_{15} \mathrm{H}_{18} \mathrm{~N}_{8} \mathrm{O}_{2}$ )

Isolated yield: $26 \%$; white powder; $\mathrm{mp}$ : $207-210^{\circ} \mathrm{C}$; IR (KBr): $v=1639$ (CO-acetyl), 2918 (CH-aliph), 3100 (CH-aryl), $3307(\mathrm{NH}), 3398(\mathrm{OH}) \mathrm{cm}^{-1}$; ${ }^{1} \mathrm{H}-\mathrm{NMR}\left(600 \mathrm{MHz}, \mathrm{D}_{2} \mathrm{O}\right)$ $\delta=2.24\left(\mathrm{q}, J=6.6 \mathrm{~Hz}, 3 \mathrm{H}, \mathrm{CH}_{3}\right), 3.57\left(\mathrm{t}, J=6.8 \mathrm{~Hz}, 2 \mathrm{H}, \mathrm{CH}_{2}\right)$, $4.16\left(\mathrm{~s}, 2 \mathrm{H}, \mathrm{CH}_{2}\right), 6.22(\mathrm{~s}, 2 \mathrm{H}, \mathrm{NH}), 7.05(\mathrm{~d}, J=7.8 \mathrm{~Hz}, 2 \mathrm{H}$, ArH), 7.69 (s, 2H, ArH), 8.07 (s, H, CH), 8.97 (s, H, NH), 11.90 (s, H, OH) ppm; ${ }^{13} \mathrm{C}-\mathrm{NMR}\left(151 \mathrm{MHz}, \mathrm{DMSO}-d_{6}\right)$ $\delta=20.30,36.37,39.03,114.33,119.19,121.19,122.27,127.96$, 129.65, 129.79, 133.16, 155.72 ppm; HR-MS-ESI: $m / z=343.1631$ $\left([\mathrm{M}+\mathrm{H}]^{+}\right.$, Calcd), 343.1626 (Found).

1-(2-(2-(4-Hydroxyphenyl)amino)-9H-purin-6-yl)amino)ethyl)-3-hydroxyurea $\left(4 \mathbf{i}, \mathrm{C}_{14} \mathrm{H}_{16} \mathrm{~N}_{8} \mathrm{O}_{3}\right)$

Isolated yield: $52 \%$; white powder; $\mathrm{mp}$ : $178-180^{\circ} \mathrm{C}$; IR (KBr): $v=1581$ (CO-acetyl), 2939 (CH-aliph), 3000-3400 (br. $\mathrm{CH}$-aryl, $\mathrm{NH}, \mathrm{OH}) \mathrm{cm}^{-1}$; ${ }^{1} \mathrm{H}-\mathrm{NMR}\left(600 \mathrm{MHz}, \mathrm{DMSO}-d_{6}\right)$ $\delta=3.55\left(\mathrm{t}, J=6.6 \mathrm{~Hz}, 2 \mathrm{H}, \mathrm{CH}_{2}\right), 4.13\left(\mathrm{t}, J=5.6 \mathrm{~Hz}, 2 \mathrm{H}, \mathrm{CH}_{2}\right)$, 6.67 (d, J=7.8 Hz, 2H, ArH), 7.53-7.56 (m, 2H, ArH), 8.07 (s, $1 \mathrm{H}, \mathrm{CH}), 8.75$ (s, 1H, NH), 8.88 (s, 1H, NH), $11.86(\mathrm{~s}, 1 \mathrm{H}, \mathrm{OH})$ ppm; ${ }^{13} \mathrm{C}-\mathrm{NMR}\left(151 \mathrm{MHz}, \mathrm{DMSO}-d_{6}\right) \delta=21.32,76.10,129.28$, $129.65,129.84,131.16,139.07,153.57,154.21,168.50$ ppm; HRMS-ESI: $m / z=343.1267$ ([M-H]', Calcd), 343.1261 (Found).

1-(3-(2-(4-Methyl-phenyl)amino)-9H-purin-6-yl)amino)propyl)-3-hydroxyurea $\left(4 \mathbf{j}, \mathrm{C}_{16} \mathrm{H}_{20} \mathrm{~N}_{8} \mathrm{O}_{2}\right)$

Isolated yield: $20 \%$; white powder; mp: $220-223^{\circ} \mathrm{C}$; IR (KBr): $v=1627$ (CO-acetyl), 2922 (CH-aliph), $3061 \quad(\mathrm{CH}-$ aryl), 3200-3400 (br NH, OH) $\mathrm{cm}^{-1}$; ${ }^{1} \mathrm{H}-\mathrm{NMR}(600 \mathrm{MHz}$, DMSO- $\left.d_{6}\right) \delta=1.09\left(\mathrm{t}, J=6.0 \mathrm{~Hz}, 2 \mathrm{H}, \mathrm{CH}_{2}\right), 1.72\left(\mathrm{~s}, 3 \mathrm{H}, \mathrm{CH}_{3}\right)$, $3.16\left(\mathrm{t}, J=6.0 \mathrm{~Hz}, 2 \mathrm{H}, \mathrm{CH}_{2}\right), 3.30-3.33\left(\mathrm{~m}, 2 \mathrm{H}, \mathrm{CH}_{2}\right), 5.93$ (d, $J=9.6 \mathrm{~Hz}, 2 \mathrm{H}, \mathrm{NH}), 6.82-6.85(\mathrm{~m}, 2 \mathrm{H}, \mathrm{ArH}), 7.22(\mathrm{t}$, $J=7.2 \mathrm{~Hz}, 2 \mathrm{H}, \mathrm{ArH}), 7.71$ (s, 1H, NH), 7.73 (s, 1H, NH), 7.83 $(\mathrm{s}, 1 \mathrm{H}, \mathrm{CH}), 8.30(\mathrm{~s}, 1 \mathrm{H}, \mathrm{NH}) \mathrm{ppm} ;{ }^{13} \mathrm{C}-\mathrm{NMR}(151 \mathrm{MHz}$, DMSO- $\left.d_{6}\right) \quad \delta=20.23,64.78,79.18$, 118.92, 119.76, 128.11, $129.41, \quad 141.75, \quad 156.21, \quad 161.51,178.66$ ppm; HR-MS-ESI: $m / z=357.1787\left([\mathrm{M}+\mathrm{H}]^{+}\right.$, Calcd), 357.1785 (Found).

1-(3-(2-(4-Hydroxyphenyl)amino)-9H-purin-6-yl)amino)propyl)-3-hydroxyurea $\left(4 \mathbf{k}, \mathrm{C}_{15} \mathrm{H}_{18} \mathrm{~N}_{8} \mathrm{O}_{3}\right)$

Isolated yield: $25 \%$; white powder; mp: $184-187^{\circ} \mathrm{C}$; IR (KBr): $v=1624$ (CO-acetyl), 2901 (CH-aliph), 3022 (CH-aryl), $3220(\mathrm{NH}), 3438(\mathrm{OH}) \mathrm{cm}^{-1}$; ${ }^{1} \mathrm{H}-\mathrm{NMR}(600 \mathrm{MHz}$, DMSOd $) \delta=1.09\left(\mathrm{t}, J=6.6 \mathrm{~Hz}, 1 \mathrm{H}, \mathrm{CH}_{2}\right), 1.67-1.72\left(\mathrm{~m}, 2 \mathrm{H}, \mathrm{CH}_{2}\right)$, 3.27-3.30 (m, 2H, $\left.\mathrm{CH}_{2}\right), 3.51(\mathrm{~s}, 1 \mathrm{H}, \mathrm{OH}), 5.90(\mathrm{~s}, 2 \mathrm{H}, \mathrm{NH})$, 6.67 (q, $J=8.4 \mathrm{~Hz}, 2 \mathrm{H}, \mathrm{ArH}), 7.54$ (t, $J=6.0 \mathrm{~Hz}, 2 \mathrm{H}, \mathrm{ArH}), 7.71$ (s, 1H, NH), 7.73 (s, 1H, NH), $8.32(\mathrm{~s}, 1 \mathrm{H}, \mathrm{NH}) \mathrm{ppm} ;{ }^{13} \mathrm{C}-\mathrm{NMR}$ $\left(151 \mathrm{MHz}, \mathrm{DMSO}-d_{6}\right) \delta=21.31,27.56,36.57,39.59,115.22$, $119.17,120.61,127.94,128.32,180.77$ ppm; HR-MS-ESI: $m / z=359.1580\left([\mathrm{M}+\mathrm{H}]^{+}\right.$, Calcd). Found (359.1585).

1-(3-(2-(4-Methoxyphenyl)amino)-9H-purin-6-yl)amino)propyl)-3-hydroxyurea (4l, $\mathrm{C}_{16} \mathrm{H}_{20} \mathrm{~N}_{8} \mathrm{O}_{3}$ )

Isolated yield: $36 \%$; white powder; mp: $196-199^{\circ} \mathrm{C}$; IR (KBr): $v=1620$ (CO-acetyl), 2935 (CH-aliph), $3366(\mathrm{NH})$ $\mathrm{cm}^{-1} ;{ }^{1} \mathrm{H}-\mathrm{NMR}\left(600 \mathrm{MHz}, \mathrm{DMSO}-d_{6}\right) \delta=1.71(\mathrm{t}, J=6.6 \mathrm{~Hz}$, $\left.2 \mathrm{H}, \mathrm{CH}_{2}\right), 2.39\left(\mathrm{~s}, 3 \mathrm{H}, \mathrm{CH}_{3}\right), 3.15\left(\mathrm{t}, J=6.6 \mathrm{~Hz}, 2 \mathrm{H}, \mathrm{CH}_{2}\right), 3.49$ $\left(\mathrm{t}, J=6.6 \mathrm{~Hz}, 2 \mathrm{H}, \mathrm{CH}_{2}\right), 6.97(\mathrm{~s}, 1 \mathrm{H}, \mathrm{NH}), 7.03(\mathrm{~d}, J=8.4 \mathrm{~Hz}$, 2H, ArH), 7.51 (s, 1H, NH), 7.69 (d, J=7.8 Hz, 2H, ArH), 7.76 (s, 1H, NH), 8.32 (s, 1H, NH), $8.62(\mathrm{~s}, 1 \mathrm{H}, \mathrm{CH}), 8.67(\mathrm{~s}, 1 \mathrm{H}$, $\mathrm{NH}), 12.42$ (s, 1H, OH) ppm; ${ }^{13} \mathrm{C}-\mathrm{NMR}(151 \mathrm{MHz}, \mathrm{DMSO}-$ $\left.d_{6}\right) \delta=20.30,36.39,39.90,119.17,128.83,152.58,158.51$, 158.72 ppm; HR-MS-ESI: $m / z=395.1556\left([\mathrm{M}+\mathrm{Na}]^{+}\right.$, Calcd $)$, 395.1545 (Found).

General Synthetic Method of Compounds 5 $5 b^{\prime}-5 i^{\prime} \quad$ Compounds $\mathbf{5} \mathbf{b}^{\prime}-\mathbf{i}^{\prime}$ could be obtained by reaction of 2,6-dichloro- $9 H$-purine and different aliphatic amines and aromatic amines, their synthesis methods were same as that of $\mathbf{1 a - 1 d}$.

2-Chloro-6-methylamino-9H-purine (5 $\left.\mathbf{5} \mathbf{b}^{\prime}, \mathrm{C}_{6} \mathrm{H}_{6} \mathrm{ClN}_{5}\right)$

White solid; yield $1.6 \mathrm{~g}$ (89\%); mp: $275-276^{\circ} \mathrm{C}$; IR ( $\left.\mathrm{KBr}\right)$ : $v=1651(\mathrm{NH}), 2831$ (CH-aliph), $3419(\mathrm{NH}) \mathrm{cm}^{-1}$.

2-Chloro-6-ethylamino-9H-purin $\left(\mathbf{5} \mathbf{c}^{\prime}, \mathrm{C}_{7} \mathrm{H}_{8} \mathrm{ClN}_{5}\right)$

White solid; yield $1.8 \mathrm{~g}$ (92\%); mp: $279-280^{\circ} \mathrm{C}$; IR (KBr): $v=1651(\mathrm{NH}), 2877$ (CH-aliph), $3419(\mathrm{NH}) \mathrm{cm}^{-1}$.

2-Chloro-6-propylamino-9H-purin $\left(\mathbf{5} \mathbf{d}^{\prime}, \mathrm{C}_{8} \mathrm{H}_{10} \mathrm{ClN}_{5}\right)$

White solid; yield $1.8 \mathrm{~g}(85 \%)$; mp: $>300^{\circ} \mathrm{C}$; IR $(\mathrm{KBr})$ : $v=1651(\mathrm{NH}), 2877$ (CH-aliph), $3419(\mathrm{NH}) \mathrm{cm}^{-1}$.

2-Chloro-6-phenylamino-9H-purin $\left(\mathbf{5 e}^{\prime}, \mathrm{C}_{11} \mathrm{H}_{8} \mathrm{ClN}_{5}\right)$

White solid; yield $1.9 \mathrm{~g}(76 \%)$; mp: $297-298^{\circ} \mathrm{C}$; IR (KBr): $v=1651(\mathrm{NH}), 2881$ (CH-aliph), $3081(\mathrm{CH}$-aryl), $3411(\mathrm{NH})$ $\mathrm{cm}^{-1}$.

2-Chloro-6-(4-methylphenyl)amino-9H-purin (5f', $\left.\mathrm{C}_{12} \mathrm{H}_{10} \mathrm{ClN}_{5}\right)$ White solid; yield $1.9 \mathrm{~g}$ (75\%); mp: $>300^{\circ} \mathrm{C}$; IR (KBr): $v=1651(\mathrm{NH}), 2877$ (CH-aliph), $3197(\mathrm{CH}$-aryl), $3415(\mathrm{NH})$ $\mathrm{cm}^{-1}$.

2-Chloro-6-(4-methoxyphenyl)amino-9H-purin $\left(\mathbf{5 g} \mathbf{g}^{\prime}, \mathrm{C}_{12} \mathrm{H}_{10} \mathrm{ClN}_{5} \mathrm{O}\right)$ White solid; yield $2.2 \mathrm{~g}(81 \%)$; $\mathrm{mp}$ : $>300^{\circ} \mathrm{C}$; IR $(\mathrm{KBr})$ : $v=1666(\mathrm{NH}), 2864(\mathrm{CH}$-aliph), $3074(\mathrm{CH}$-aryl), $3435(\mathrm{NH})$ $\mathrm{cm}^{-1}$.

2-Chloro-6-(4-chlorophenyl)amino-9H-purin (5h', $\left.\mathrm{C}_{11} \mathrm{H}_{7} \mathrm{Cl}_{2} \mathrm{~N}_{5}\right)$ White solid; yield $1.9 \mathrm{~g}(69 \%)$; mp: $>300^{\circ} \mathrm{C}$; IR $(\mathrm{KBr})$ : $v=1643(\mathrm{NH}), 2937$ (CH-aliph), $3217(\mathrm{NH}) \mathrm{cm}^{-1}$.

2-Chloro-6-(4-hydroxyphenyl)amino-9H-purin (5i', $\left.\mathrm{C}_{11} \mathrm{H}_{8} \mathrm{ClN}_{5} \mathrm{O}\right)$ White solid; yield $1.9 \mathrm{~g}(72 \%)$; $\mathrm{mp}$ : $>300^{\circ} \mathrm{C}$; IR $(\mathrm{KBr})$ : 
$v=2879$ (CH-aliph), 3062 (CH-aryl), 3200-3400 (br NH, OH) $\mathrm{cm}^{-1}$.

General Synthetic Method of Compounds $6 a^{\prime}-6 p^{\prime}$ 2,6-dichloro- $9 H$-purine $(5 \mathrm{mmol})$ or intermediates $\mathbf{5}$ was dissolved in $20 \mathrm{~mL}$ anhydrous DMF, then $\mathrm{K}_{2} \mathrm{CO}_{3}(8 \mathrm{mmol})$ was added, and ethyl 4-bromobutanoate or ethyl 8-bromooctanoate $(8 \mathrm{mmol})$ was dropped into the solution. Cut off from the air, the solution was stirred at room temperature for overnight, and then adjusted to $\mathrm{pH} 7-8$ with $\mathrm{HCl}(1 \mathrm{~mol} / \mathrm{L})$, then extracted with $50 \mathrm{~mL} \times 3$ ethyl acetate and the organic phase was combined, and washed with brine, dried over $\mathrm{MgSO}_{4}$ and evaporated. The crude product was purified by chromatography on a silica gel column (EtOAc/petroleum ether, $1: 1)$ to give desired compounds $\mathbf{6} \mathbf{a}^{\prime}-\mathbf{6} \mathbf{p}^{\prime}$.

Ethyl-4-(2,6-dichloro-9H-purin-9-yl)butanoate $\left(\mathbf{6 a}^{\prime}, \mathrm{C}_{11} \mathrm{H}_{12} \mathrm{Cl}_{2} \mathrm{~N}_{4} \mathrm{O}_{2}\right)$ Isolated yield: $82 \%$; light yellow oil; IR (KBr): $v=1541$ (CO-acetyl), 2935 (CH-aliph), $3338(\mathrm{NH}) \quad \mathrm{cm}^{-1} ;{ }^{1} \mathrm{H}-\mathrm{NMR}$ $\left(600 \mathrm{MHz}, \mathrm{DMSO}-d_{6}\right) \delta=1.15\left(\mathrm{t}, J=7.2 \mathrm{~Hz}, 3 \mathrm{H}, \mathrm{CH}_{3}\right), 2.04$ (t, $\left.J=7.2 \mathrm{~Hz}, 2 \mathrm{H}, \mathrm{CH}_{2}\right), 2.30\left(\mathrm{t}, J=7.2 \mathrm{~Hz}, 2 \mathrm{H}, \mathrm{CH}_{2}\right), 2.50(\mathrm{q}$, $\left.J=7.8 \mathrm{~Hz}, 2 \mathrm{H}, \mathrm{CH}_{2}\right), 4.14\left(\mathrm{t}, J=7.2 \mathrm{~Hz}, 2 \mathrm{H}, \mathrm{CH}_{2}\right), 8.13(\mathrm{~s}, 1 \mathrm{H}$, CH) ppm.

Ethyl-4-(2-chloro-6-methylamino-9H-purin-9-yl)butanoate $\left(\mathbf{6} \mathbf{b}^{\prime}, \mathrm{C}_{12} \mathrm{H}_{16} \mathrm{ClN}_{5} \mathrm{O}_{2}\right)$

Isolated yield: $83 \%$; light yellow oil; IR (KBr): $v=1643$ (CO-acetyl), 2937 (CH-aliph), $3217(\mathrm{NH}) \mathrm{cm}^{-1} ;{ }^{1} \mathrm{H}-\mathrm{NMR}$ $\left(600 \mathrm{MHz}, \mathrm{DMSO}-d_{6}\right) \delta=1.15\left(\mathrm{t}, J=7.2 \mathrm{~Hz}, 3 \mathrm{H}, \mathrm{CH}_{3}\right), 2.04$ (t, $\left.J=7.2 \mathrm{~Hz}, 2 \mathrm{H}, \mathrm{CH}_{2}\right), 2.29\left(\mathrm{t}, J=7.2 \mathrm{~Hz}, 2 \mathrm{H}, \mathrm{CH}_{2}\right), 2.92$ (d, $\left.J=4.2 \mathrm{~Hz}, 3 \mathrm{H}, \mathrm{CH}_{3}\right), 3.99\left(\mathrm{q}, J=7.2 \mathrm{~Hz}, 2 \mathrm{H}, \mathrm{CH}_{2}\right), 4.14(\mathrm{t}$, $\left.J=6.6 \mathrm{~Hz}, 2 \mathrm{H}, \mathrm{CH}_{2}\right), 8.12(\mathrm{~s}, 1 \mathrm{H}, \mathrm{CH}), 8.15(\mathrm{~s}, 1 \mathrm{H}, \mathrm{NH}) \mathrm{ppm}$.

Ethyl-4-(2-chloro-6-ethylamino-9H-purin-9-yl)butanoate $\left(6 \mathbf{c}^{\prime}, \mathrm{C}_{13} \mathrm{H}_{18} \mathrm{ClN}_{5} \mathrm{O}_{2}\right)$

Isolated yield: 79\%; colorless oil; IR (KBr): $v=1620$ (CO-acetyl), 2943 (CH-aliph), $3348(\mathrm{NH}) \mathrm{cm}^{-1}$; ${ }^{1} \mathrm{H}-\mathrm{NMR}$ $\left(600 \mathrm{MHz}, \mathrm{DMSO}-d_{6}\right) \delta=1.12-1.17\left(\mathrm{~m}, 6 \mathrm{H}, \mathrm{CH}_{3}\right), 2.05(\mathrm{q}$, $\left.J=6.6 \mathrm{~Hz}, 2 \mathrm{H}, \mathrm{CH}_{2}\right), 2.29$ (t, $\left.J=7.2 \mathrm{~Hz}, 2 \mathrm{H}, \mathrm{CH}_{2}\right), 3.44$ (t, $\left.J=6.0 \mathrm{~Hz}, 2 \mathrm{H}, \mathrm{CH}_{2}\right), 3.96-4.00\left(\mathrm{~m}, 2 \mathrm{H}, \mathrm{CH}_{2}\right), 4.14(\mathrm{t}$, $\left.J=7.2 \mathrm{~Hz}, 2 \mathrm{H}, \mathrm{CH}_{2}\right), 8.11(\mathrm{~s}, 1 \mathrm{H}, \mathrm{CH}), 8.21(\mathrm{~s}, 1 \mathrm{H}, \mathrm{NH}) \mathrm{ppm}$.

Ethyl-4-(2-chloro-6-propylamino-9H-purin-9-yl)butanoate $\left(\mathbf{6} \mathbf{d}^{\prime}, \mathrm{C}_{14} \mathrm{H}_{20} \mathrm{ClN}_{5} \mathrm{O}_{2}\right)$

Isolated yield: 71\%; colorless oil; IR (KBr): $v=1651$ (CO-acetyl), 2877 (CH-aliph), $3200(\mathrm{NH}) \mathrm{cm}^{-1} ;{ }^{1} \mathrm{H}-\mathrm{NMR}$ $\left(600 \mathrm{MHz}, \mathrm{DMSO}-d_{6}\right) \delta=0.87\left(\mathrm{t}, J=7.2 \mathrm{~Hz}, 3 \mathrm{H}, \mathrm{CH}_{3}\right), 1.15$ $\left(\mathrm{t}, J=7.2 \mathrm{~Hz}, 3 \mathrm{H}, \mathrm{CH}_{3}\right), 1.60\left(\mathrm{t}, J=7.2 \mathrm{~Hz}, 2 \mathrm{H}, \mathrm{CH}_{2}\right), 2.06(\mathrm{t}$, $\left.J=7.2 \mathrm{~Hz}, 2 \mathrm{H}, \mathrm{CH}_{2}\right), 2.31\left(\mathrm{t}, J=7.2 \mathrm{~Hz}, 2 \mathrm{H}, \mathrm{CH}_{2}\right), 3.35-3.40$ (m, $\left.2 \mathrm{H}, \mathrm{CH}_{2}\right), 4.02\left(\mathrm{t}, J=7.2 \mathrm{~Hz}, 2 \mathrm{H}, \mathrm{CH}_{2}\right), 4.15(\mathrm{t}, J=7.2 \mathrm{~Hz}$, $\left.2 \mathrm{H}, \mathrm{CH}_{2}\right), 8.13(\mathrm{~s}, 1 \mathrm{H}, \mathrm{CH}), 8.27(\mathrm{~s}, 1 \mathrm{H}, \mathrm{NH}) \mathrm{ppm}$.

Ethyl-4-(2-chloro-6-phenylamino-9H-purin-9-yl)butanoate $\left(6 \mathbf{e}^{\prime}, \mathrm{C}_{17} \mathrm{H}_{18} \mathrm{ClN}_{5} \mathrm{O}_{2}\right)$

Isolated yield: $69 \%$; white soild; mp: $133-134^{\circ} \mathrm{C}$; IR (KBr): $v=1651$ (CO-acetyl), 2877 (CH-aliph), 3060 (CH-aryl), $3419(\mathrm{NH}) \mathrm{cm}^{-1} ;{ }^{1} \mathrm{H}-\mathrm{NMR}\left(600 \mathrm{MHz}, \mathrm{DMSO}-d_{6}\right) \delta=1.15(\mathrm{t}$, $\left.J=7.2 \mathrm{~Hz}, 3 \mathrm{H}, \mathrm{CH}_{3}\right), 2.08$ (q, $\left.J=5.4 \mathrm{~Hz}, 2 \mathrm{H}, \mathrm{CH}_{2}\right), 2.34$ (t, $\left.J=7.2 \mathrm{~Hz}, 2 \mathrm{H}, \mathrm{CH}_{2}\right), 4.00\left(\mathrm{t}, J=7.2 \mathrm{~Hz}, 2 \mathrm{H}, \mathrm{CH}_{2}\right), 4.20(\mathrm{t}$, $\left.J=7.2 \mathrm{~Hz}, 2 \mathrm{H}, \mathrm{CH}_{2}\right), 7.09(\mathrm{q}, J=7.2 \mathrm{~Hz}, 1 \mathrm{H}, \mathrm{ArH}), 7.36(\mathrm{q}$, $J=7.2 \mathrm{~Hz}, 2 \mathrm{H}, \mathrm{ArH}), 7.84$ (q, $J=7.8 \mathrm{~Hz}, 2 \mathrm{H}, \operatorname{ArH}), 8.31$ (s, $1 \mathrm{H}$, $\mathrm{CH}), 10.25$ (s, 1H, NH) ppm.

Ethyl-4-(2-chloro-6-(4-methylphenyl)amino-9H-purin-9yl)butanoate $\left(\mathbf{6} \mathbf{f}^{\prime}, \mathrm{C}_{18} \mathrm{H}_{20} \mathrm{ClN}_{5} \mathrm{O}_{2}\right)$

Isolated yield: $70 \%$; white soild; $\mathrm{mp}: 177-180^{\circ} \mathrm{C}$; IR ( $\mathrm{KBr}$ ): $v=1600$ (CO-acetyl), 2970 (CH-aliph), 3058 (CH-aryl), 3458 (NH) $\mathrm{cm}^{-1}$; ${ }^{1} \mathrm{H}-\mathrm{NMR} \quad\left(600 \mathrm{MHz},{ }^{\mathrm{DMSO}-} d_{6}\right) \quad \delta=1.12 \quad(\mathrm{t}$,
$\left.J=7.2 \mathrm{~Hz}, 3 \mathrm{H}, \mathrm{CH}_{3}\right), 2.07$ (q, $\left.J=7.2 \mathrm{~Hz}, 2 \mathrm{H}, \mathrm{CH}_{2}\right), 2.26(\mathrm{~s}, 3 \mathrm{H}$, $\left.\mathrm{CH}_{3}\right), 2.31\left(\mathrm{t}, J=7.2 \mathrm{~Hz}, 2 \mathrm{H}, \mathrm{CH}_{2}\right), 3.97\left(\mathrm{~m}, 2 \mathrm{H}, \mathrm{CH}_{2}\right), 4.18$ (t, $\left.J=6.6 \mathrm{~Hz}, 2 \mathrm{H}, \mathrm{CH}_{2}\right), 7.14$ (t, $\left.J=7.8 \mathrm{~Hz}, 2 \mathrm{H}, \mathrm{ArH}\right), 7.69$ (d, $J=8.4 \mathrm{~Hz}, 2 \mathrm{H}, \mathrm{ArH}), 8.27(\mathrm{~s}, 1 \mathrm{H}, \mathrm{CH}), 10.18(\mathrm{~s}, 1 \mathrm{H}, \mathrm{NH}) \mathrm{ppm}$.

Ethyl-4-(2-chloro-6-(4-methoxyphenyl)amino-9H-purin-9yl)butanoate $\left(\mathbf{6 g}^{\prime}, \mathrm{C}_{18} \mathrm{H}_{20} \mathrm{ClN}_{5} \mathrm{O}_{3}\right)$

Isolated yield: $62 \%$; light yellow soild; mp: $90-92^{\circ} \mathrm{C}$; IR (KBr): $v=1577$ (CO-acetyl), 2980 (CH-aliph), 3071 (CH-aryl), $3201(\mathrm{NH}) \mathrm{cm}^{-1}$; ${ }^{1} \mathrm{H}-\mathrm{NMR}\left(600 \mathrm{MHz}\right.$, DMSO- $\left.d_{6}\right) \quad \delta=1.13$ (t, $\left.J=7.2 \mathrm{~Hz}, 3 \mathrm{H}, \mathrm{CH}_{3}\right), 2.08\left(\mathrm{t}, J=7.2 \mathrm{~Hz}, 2 \mathrm{H}, \mathrm{CH}_{2}\right), 2.32$ (t, $\left.J=7.2 \mathrm{~Hz}, 2 \mathrm{H}, \mathrm{CH}_{2}\right), 2.88\left(\mathrm{~s}, 2 \mathrm{H}, \mathrm{CH}_{2}\right), 3.75\left(\mathrm{~s}, 3 \mathrm{H}, \mathrm{CH}_{3}\right), 4.18$ $\left(\mathrm{t}, J=6.6 \mathrm{~Hz}, 2 \mathrm{H}, \mathrm{CH}_{2}\right), 6.94(\mathrm{~d}, J=2.4 \mathrm{~Hz}, 2 \mathrm{H}, \mathrm{ArH}), 7.69(\mathrm{~d}$, $J=9.0 \mathrm{~Hz}, 2 \mathrm{H}, \mathrm{ArH}), 8.28(\mathrm{~s}, 1 \mathrm{H}, \mathrm{CH}), 10.13(\mathrm{~s}, 1 \mathrm{H}, \mathrm{NH}) \mathrm{ppm}$.

Ethyl-4-(2-chloro-6-(4-chlorophenyl)amino-9H-purin-9yl)butanoate $\left(\mathbf{6} \mathbf{h}^{\prime}, \mathrm{C}_{17} \mathrm{H}_{17} \mathrm{Cl}_{2} \mathrm{~N}_{5} \mathrm{O}_{2}\right)$

Isolated yield: 77\%; colorless oil; IR (KBr): $v=1633$ (COacetyl), 2937 (CH-aliph), 3081 (CH-aryl), $3417(\mathrm{NH}) \mathrm{cm}^{-1}$; ${ }^{1} \mathrm{H}-\mathrm{NMR}\left(600 \mathrm{MHz}, \mathrm{DMSO}-d_{6}\right) \delta=1.13\left(\mathrm{t}, J=7.2 \mathrm{~Hz}, 3 \mathrm{H}, \mathrm{CH}_{3}\right)$, 2.08 (t, $J=7.2 \mathrm{~Hz}, 2 \mathrm{H}, \mathrm{CH}_{2}$ ), 2.33 (t, $\left.J=7.2 \mathrm{~Hz}, 2 \mathrm{H}, \mathrm{CH}_{2}\right), 3.98$ (q, $\left.J=7.2 \mathrm{~Hz}, 2 \mathrm{H}, \mathrm{CH}_{2}\right), 4.20\left(\mathrm{t}, J=6.6 \mathrm{~Hz}, 2 \mathrm{H}, \mathrm{CH}_{2}\right), 7.40(\mathrm{~d}$, $J=8.4 \mathrm{~Hz}, 2 \mathrm{H}, \mathrm{ArH}), 7.89(\mathrm{~d}, J=9.0 \mathrm{~Hz}, 2 \mathrm{H}, \mathrm{ArH}), 8.32(\mathrm{~s}, 1 \mathrm{H}$, $\mathrm{CH}), 10.41(\mathrm{~s}, 1 \mathrm{H}, \mathrm{NH}) \mathrm{ppm}$.

Ethyl-4-(2-chloro-6-(4-hydroxyphenyl)amino-9H-purin-9yl)butanoate $\left(6 \mathbf{i}^{\prime}, \mathrm{C}_{17} \mathrm{H}_{18} \mathrm{ClN}_{5} \mathrm{O}_{3}\right)$

Isolated yield: $77 \%$; light yellow soild; $\mathrm{mp}: 162-164^{\circ} \mathrm{C}$; IR (KBr): $v=786,825,1031,1178,1238,1429,1500,1620$, $2935,3365 \mathrm{~cm}^{-1}$; ${ }^{1} \mathrm{H}-\mathrm{NMR}\left(600 \mathrm{MHz}, \mathrm{DMSO}-d_{6}\right) \delta=1.17(\mathrm{t}$, $\left.J=7.2 \mathrm{~Hz}, 3 \mathrm{H}, \mathrm{CH}_{3}\right), 1.79\left(\mathrm{t}, J=7.2 \mathrm{~Hz}, 2 \mathrm{H}, \mathrm{CH}_{2}\right), 2.25(\mathrm{t}$, $\left.J=7.2 \mathrm{~Hz}, 2 \mathrm{H}, \mathrm{CH}_{2}\right), 4.03\left(\mathrm{t}, J=7.2 \mathrm{~Hz}, 2 \mathrm{H}, \mathrm{CH}_{2}\right), 4.13$ (t, $\left.J=7.2 \mathrm{~Hz}, 2 \mathrm{H}, \mathrm{CH}_{2}\right), 6.75(\mathrm{~d}, J=9.0 \mathrm{~Hz}, 2 \mathrm{H}, \mathrm{ArH}), 7.52(\mathrm{~d}$, $J=8.4 \mathrm{~Hz}, 2 \mathrm{H}, \mathrm{ArH}), 8.27(\mathrm{~s}, 1 \mathrm{H}, \mathrm{CH}), 9.29(\mathrm{~s}, 1 \mathrm{H}, \mathrm{NH}), 10.00$ (s, $1 \mathrm{H}, \mathrm{OH}) \mathrm{ppm}$.

Ethyl-8-(2,6-dichloro-9H-purin-9-yl)octanoate $\left(\mathbf{6 j}^{\prime}, \mathrm{C}_{15} \mathrm{H}_{20} \mathrm{Cl}_{2} \mathrm{~N}_{4} \mathrm{O}_{2}\right)$

Isolated yield: 79\%; light yellow oil; IR (KBr): $v=1637$ (CO-acetyl), 2943 (CH-aliph) cm ${ }^{-1}$; ${ }^{1} \mathrm{H}-\mathrm{NMR} \quad(600 \mathrm{MHz}$, DMSO- $\left.d_{6}\right) \delta=1.21\left(\mathrm{t}, J=5.4 \mathrm{~Hz}, 3 \mathrm{H}, \mathrm{CH}_{3}\right), 1.26-1.27(\mathrm{~m}, 6 \mathrm{H}$, $\mathrm{CH}_{2}$ ), 1.47 (t, $\left.J=7.2 \mathrm{~Hz}, 2 \mathrm{H}, \mathrm{CH}_{2}\right), 1.80-1.85\left(\mathrm{~m}, 2 \mathrm{H}, \mathrm{CH}_{2}\right.$ ), $2.21\left(\mathrm{t}, J=7.2 \mathrm{~Hz}, 2 \mathrm{H}, \mathrm{CH}_{2}\right), 3.99\left(\mathrm{~m}, 2 \mathrm{H}, \mathrm{CH}_{2}\right), 4.23(\mathrm{~m}, 2 \mathrm{H}$, $\left.\mathrm{CH}_{2}\right), 8.10(\mathrm{~s}, 1 \mathrm{H}, \mathrm{CH}) \mathrm{ppm}$.

Ethyl-8-(2-chloro-6-propylamino-9H-purin-9-yl)octanoate $\left(6 \mathbf{k}^{\prime}, \mathrm{C}_{18} \mathrm{H}_{28} \mathrm{ClN}_{5} \mathrm{O}_{2}\right)$

Isolated yield: 71\%; colorless oil; IR (KBr): $v=1525$ (CO-acetyl), 2947 (CH-aliph), $3336(\mathrm{NH}) \quad \mathrm{cm}^{-1}$; ${ }^{1} \mathrm{H}-\mathrm{NMR}$ $\left(600 \mathrm{MHz}, \quad\right.$ DMSO- $\left.d_{6}\right) \quad \delta=0.94 \quad\left(\mathrm{t}, \quad J=6.0 \mathrm{~Hz}, 3 \mathrm{H}, \mathrm{CH}_{3}\right)$, $1.23-1.28\left(\mathrm{~m}, 5 \mathrm{H}, \mathrm{CH}_{2}, \mathrm{CH}_{3}\right), 1.49\left(\mathrm{t}, J=7.2 \mathrm{~Hz}, 2 \mathrm{H}, \mathrm{CH}_{2}\right)$, 1.60 (q, $J=7.2 \mathrm{~Hz}, 2 \mathrm{H}, \mathrm{CH}_{2}$ ), $1.77\left(\mathrm{t}, J=7.2 \mathrm{~Hz}, 2 \mathrm{H}, \mathrm{CH}_{2}\right), 2.25$ (t, $\left.J=7.8 \mathrm{~Hz}, 2 \mathrm{H}, \mathrm{CH}_{2}\right), 2.74\left(\mathrm{t}, J=7.8 \mathrm{~Hz}, 2 \mathrm{H}, \mathrm{CH}_{2}\right), 2.90$ (s, $2 \mathrm{H}, \mathrm{CH}_{2}$ ), 3.38 (t, $J=6.6 \mathrm{~Hz}, 2 \mathrm{H}, \mathrm{CH}_{2}$ ), 4.04 (t, $J=7.2 \mathrm{~Hz}, 2 \mathrm{H}$, $\left.\mathrm{CH}_{2}\right), 4.09$ (t, $\left.J=6.6 \mathrm{~Hz}, 2 \mathrm{H}, \mathrm{CH}_{2}\right), 8.16(\mathrm{~s}, 1 \mathrm{H}, \mathrm{CH}), 8.26(\mathrm{t}$, $J=5.4 \mathrm{~Hz}, 1 \mathrm{H}, \mathrm{NH}) \mathrm{ppm}$.

Ethyl-8-(2-chloro-6-phenylamino-9H-purin-9-yl)octanoate $\left(6 \mathbf{l}^{\prime}, \mathrm{C}_{21} \mathrm{H}_{26} \mathrm{ClN}_{5} \mathrm{O}_{2}\right)$

Isolated yield: $78 \%$; light yellow oil; IR (KBr): $v=1625$ (CO-acetyl), 2941 (CH-aliph), 3087 (CH-aryl), $3224(\mathrm{NH})$ $\mathrm{cm}^{-1}$; ${ }^{1} \mathrm{H}-\mathrm{NMR}\left(600 \mathrm{MHz}, \mathrm{DMSO}-d_{6}\right) \delta=1.22$ (t, $J=7.2 \mathrm{~Hz}$, $\left.3 \mathrm{H}, \mathrm{CH}_{3}\right), 1.24-1.28\left(\mathrm{~m}, 6 \mathrm{H}, \mathrm{CH}_{2}\right), 1.47(\mathrm{t}, J=7.2 \mathrm{~Hz}, 2 \mathrm{H}$, $\left.\mathrm{CH}_{2}\right), 1.79\left(\mathrm{t}, J=7.2 \mathrm{~Hz}, 2 \mathrm{H}, \mathrm{CH}_{2}\right), 2.23\left(\mathrm{t}, J=7.2 \mathrm{~Hz}, 2 \mathrm{H}, \mathrm{CH}_{2}\right.$ ), 4.01 (t, $\left.J=7.2 \mathrm{~Hz}, 2 \mathrm{H}, \mathrm{CH}_{2}\right), 4.13\left(\mathrm{t}, J=7.2 \mathrm{~Hz}, 2 \mathrm{H}, \mathrm{CH}_{2}\right), 7.08$ (s, $1 \mathrm{H}, \mathrm{ArH}), 7.36$ (q, $J=7.2 \mathrm{~Hz}, 2 \mathrm{H}, \mathrm{ArH}), 7.86(\mathrm{~d}, J=7.2 \mathrm{~Hz}$, $2 \mathrm{H}, \mathrm{ArH}), 8.33(\mathrm{~s}, 1 \mathrm{H}, \mathrm{CH}), 10.28(\mathrm{~s}, 1 \mathrm{H}, \mathrm{NH}) \mathrm{ppm}$. 
Ethyl-8-(2-chloro-6-(4-methylphenyl)amino-9H-purin-9yl)octanoate $\left(6 \mathbf{m}^{\prime}, \mathrm{C}_{22} \mathrm{H}_{28} \mathrm{ClN}_{5} \mathrm{O}_{2}\right)$

Isolated yield: $61 \%$; white soild; mp: $140-142^{\circ} \mathrm{C}$; IR (KBr): $v=1593$ (CO-acetyl), 2972 (CH-aliph), 3020 (CH-aryl), 3317 (NH) $\mathrm{cm}^{-1}$; ${ }^{1} \mathrm{H}-\mathrm{NMR} \quad\left(600 \mathrm{MHz}, \mathrm{DMSO}_{-}\right) \quad \delta=1.28 \quad(\mathrm{t}$, $\left.J=6.6 \mathrm{~Hz}, 3 \mathrm{H}, \mathrm{CH}_{3}\right), 1.47\left(\mathrm{~m}, 6 \mathrm{H}, \mathrm{CH}_{2}\right), 1.50$ (t, $J=7.2 \mathrm{~Hz}$, $\left.2 \mathrm{H}, \mathrm{CH}_{2}\right), 1.80\left(\mathrm{~m}, 2 \mathrm{H}, \mathrm{CH}_{2}\right), 2.25\left(\mathrm{~m}, 2 \mathrm{H}, \mathrm{CH}_{2}\right), 2.29(\mathrm{~s}$, $3 \mathrm{H}, \mathrm{CH}_{3}$ ), $4.03\left(\mathrm{t}, J=7.2 \mathrm{~Hz}, 2 \mathrm{H}, \mathrm{CH}_{2}\right), 4.14$ (q, $J=7.2 \mathrm{~Hz}, 2 \mathrm{H}$, $\left.\mathrm{CH}_{2}\right), 7.17(\mathrm{~d}, J=8.4 \mathrm{~Hz}, 2 \mathrm{H}, \mathrm{ArH}), 7.71(\mathrm{~d}, J=8.4 \mathrm{~Hz}, 2 \mathrm{H}$, ArH), 8.32 (s, 1H, CH), 10.20 (s, 1H, ArH) ppm.

Ethyl-8-(2-chloro-6-(4-methoxyphenyl)amino-9H-purin-9yl)octanoate (6n', $\mathrm{C}_{22} \mathrm{H}_{28} \mathrm{ClN}_{5} \mathrm{O}_{3}$ )

Isolated yield: $60 \%$; white soild; $\mathrm{mp}$ : $152-154^{\circ} \mathrm{C}$; IR (KBr): $v=1596$ (CO-acetyl), 2976 (CH-aliph), 3010 (CH-aryl), $3456(\mathrm{NH}) \mathrm{cm}^{-1}$; ${ }^{1} \mathrm{H}-\mathrm{NMR}\left(600 \mathrm{MHz}, \mathrm{DMSO}-d_{6}\right) \delta=1.16(\mathrm{t}$, $\left.J=7.2 \mathrm{~Hz}, 3 \mathrm{H}, \mathrm{CH}_{3}\right), 1.23-1.29\left(\mathrm{~m}, 6 \mathrm{H}, \mathrm{CH}_{2}\right), 1.46(\mathrm{t}, J=7.2 \mathrm{~Hz}$, $\left.2 \mathrm{H}, \mathrm{CH}_{2}\right), 2.74\left(\mathrm{t}, J=7.2 \mathrm{~Hz}, 2 \mathrm{H}, \mathrm{CH}_{2}\right), 2.90\left(\mathrm{~s}, 2 \mathrm{H}, \mathrm{CH}_{2}\right), 3.76$ (s, 3H, $\left.\mathrm{CH}_{3}\right), 4.04$ (t, J=6.0 Hz, $\left.2 \mathrm{H}, \mathrm{CH}_{2}\right), 4.14$ (t, J=6.6 Hz, $\left.2 \mathrm{H}, \mathrm{CH}_{2}\right), 6.95$ (q, $\left.J=8.9 \mathrm{~Hz}, 2 \mathrm{H}, \mathrm{ArH}\right), 7.70$ (d, $J=7.9 \mathrm{~Hz}, 2 \mathrm{H}$, ArH), 8.30 (s, 1H, CH), 10.14 (s, 1H, NH) ppm.

Ethyl-8-(2-chloro-6-(4-chlorophenyl)amino-9H-purin-9yl)octanoate $\left(\mathbf{6 o}^{\prime}, \mathrm{C}_{21} \mathrm{H}_{25} \mathrm{Cl}_{2} \mathrm{~N}_{5} \mathrm{O}_{2}\right)$

Isolated yield: $71 \%$; white soild; $\mathrm{mp}$ : $258-260^{\circ} \mathrm{C}$; IR (KBr): $v=1637$ (CO-acetyl), 2947 (CH-aliph), 3061 (CH-aryl), $3413(\mathrm{NH}) \mathrm{cm}^{-1}$; ${ }^{1} \mathrm{H}-\mathrm{NMR}\left(600 \mathrm{MHz}, \mathrm{DMSO}-d_{6}\right) \delta=1.17(\mathrm{t}$, $\left.J=7.2 \mathrm{~Hz}, 3 \mathrm{H}, \mathrm{CH}_{3}\right), 1.24-1.25\left(\mathrm{~m}, 6 \mathrm{H}, \mathrm{CH}_{2}\right), 1.49(\mathrm{t}, J=7.2 \mathrm{~Hz}$, $2 \mathrm{H}, \mathrm{CH}_{2}$ ), $1.82\left(\mathrm{t}, J=7.2 \mathrm{~Hz}, 2 \mathrm{H}, \mathrm{CH}_{2}\right), 2.25$ (t, $J=7.8 \mathrm{~Hz}, 2 \mathrm{H}$, $\left.\mathrm{CH}_{2}\right), 4.04\left(\mathrm{q}, J=7.2 \mathrm{~Hz}, 2 \mathrm{H}, \mathrm{CH}_{2}\right), 4.17(\mathrm{t}, J=6.6 \mathrm{~Hz}, 2 \mathrm{H}$, $\left.\mathrm{CH}_{2}\right), 7.42$ (d, $\left.J=9.2 \mathrm{~Hz}, 2 \mathrm{H}, \mathrm{ArH}\right), 7.92(\mathrm{~d}, J=8.0 \mathrm{~Hz}, 2 \mathrm{H}$, $\mathrm{ArH}), 8.37$ (s, 1H, CH), 10.44 (s, 1H, NH) ppm.

Ethyl-8-(2-chloro-6-(4-hydroxyphenyl)amino-9H-purin-9yl)octanoate $\left(6 \mathbf{p}^{\prime}, \mathrm{C}_{21} \mathrm{H}_{26} \mathrm{ClN}_{5} \mathrm{O}_{3}\right)$

Isolated yield: $71 \%$; white soild; $\mathrm{mp}: 158-160^{\circ} \mathrm{C}$; IR (KBr): $v=1633$ (CO-acetyl), 2837 (CH-aliph), 3090 (CH-aryl), $3332(\mathrm{NH}) \quad \mathrm{cm}^{-1}$; ${ }^{1} \mathrm{H}-\mathrm{NMR}\left(600 \mathrm{MHz}, \mathrm{DMSO}-d_{6}\right) \quad \delta=1.22$ (t, $\left.J=6.0 \mathrm{~Hz}, 3 \mathrm{H}, \mathrm{CH}_{3}\right), 1.24-1.26\left(\mathrm{~m}, 6 \mathrm{H}, \mathrm{CH}_{2}\right), 1.49$ (t, $\left.J=7.2 \mathrm{~Hz}, 2 \mathrm{H}, \mathrm{CH}_{2}\right), 1.80\left(\mathrm{t}, J=7.2 \mathrm{~Hz}, 2 \mathrm{H}, \mathrm{CH}_{2}\right), 2.24$ (t, $\left.J=7.2 \mathrm{~Hz}, 2 \mathrm{H}, \mathrm{CH}_{2}\right), 4.03\left(\mathrm{t}, J=6.6 \mathrm{~Hz}, 2 \mathrm{H}, \mathrm{CH}_{2}\right), 4.13$ (t, $\left.J=6.6 \mathrm{~Hz}, 2 \mathrm{H}, \mathrm{CH}_{2}\right), 6.75(\mathrm{~d}, J=9.0 \mathrm{~Hz}, 2 \mathrm{H}, \mathrm{ArH}), 7.52(\mathrm{~d}$, $J=8.4 \mathrm{~Hz}, 2 \mathrm{H}, \mathrm{ArH}), 8.27$ (s, 1H, CH), 9.29 (s, 1H, NH), 10.00 (s, 1H, OH) ppm.

General Synthetic Method of Compounds $7 \mathbf{a}^{\prime}-7 \mathbf{p}^{\prime}$ At room temperature, to a solution of hydroxylamine hydrochloride $(2.0 \mathrm{mmol})$ in anhydrous methanol $(20 \mathrm{~mL}), 4 \mathrm{mmol}$ new sodium methoxide was dropped into methanol. After stirring for $30 \mathrm{~min}$ at room temperature, compounds $6(1.0 \mathrm{mmol})$ were added, and the mixture was stirred for $12 \mathrm{~h}$ at $60^{\circ} \mathrm{C}$. Upon completion, most of the methanol was evaporated, the residue was adjusted to $\mathrm{pH} 5-6$ with $\mathrm{HCl}(1 \mathrm{~mol} / \mathrm{L})$. The solution was concentrated under reduced pressure and the crude product was purified by chromatography on a silica gel column (methanol/ EtOAc, $1: 20)$ to give compounds $7 \mathbf{a}^{\prime}-7 \mathbf{p}^{\prime}$.

4-(2,6-Dichloro-9H-purin-9-yl)- $N$-hydroxybutanamide $\mathrm{C}_{9} \mathrm{H}_{9} \mathrm{Cl}_{2} \mathrm{~N}_{5} \mathrm{O}_{2}$ )

Isolated yield: 67\%; white powder; mp: $90-92^{\circ} \mathrm{C}$; IR (KBr): $v=1570$ (CO-acetyl), 2959 (CH-aliph), 3094 (CH-aryl), $3453(\mathrm{OH}) \mathrm{cm}^{-1}$; ${ }^{1} \mathrm{H}-\mathrm{NMR}\left(600 \mathrm{MHz}, \mathrm{DMSO}-d_{6}\right) \quad \delta=2.05$ $\left(\mathrm{t}, J=9.0 \mathrm{~Hz}, 2 \mathrm{H}, \mathrm{CH}_{2}\right), 2.25\left(\mathrm{t}, J=9.0 \mathrm{~Hz}, 2 \mathrm{H}, \mathrm{CH}_{2}\right), 4.23$ (t, J=9.0 Hz, 2H, $\left.\mathrm{CH}_{2}\right), 8.41(\mathrm{~s}, 1 \mathrm{H}, \mathrm{CH}), 12.12(\mathrm{~s}, 1 \mathrm{H}, \mathrm{OH})$ ppm; ${ }^{13} \mathrm{C}-\mathrm{NMR}\left(151 \mathrm{MHz}, \mathrm{DMSO}-d_{6}\right) \quad \delta=25.2,31.1,60.4$, $116.3,142.0,151.1,153.5,156.3,172.5$ ppm; HR-MS-ESI: $m / z=288.0055\left([\mathrm{M}-\mathrm{H}]^{-}\right.$, Calcd). Found (288.0066).

4-(2-Chloro-6-methylamino-9H-purin-9-yl)- $N$-hydroxybutanamide $\left(\mathbf{7 b}^{\prime}, \mathrm{C}_{10} \mathrm{H}_{13} \mathrm{ClN}_{6} \mathrm{O}_{2}\right)$

Isolated yield: $53 \%$; white powder; $\mathrm{mp}: 112-113^{\circ} \mathrm{C}$; IR (KBr): $v=1653$ (CO-acetyl), 2880 (CH-aliph), 3055 (CH-aryl), $3306(\mathrm{NH}), 3400(\mathrm{OH}) \mathrm{cm}^{-1}$; ${ }^{1} \mathrm{H}-\mathrm{NMR}\left(600 \mathrm{MHz}, \mathrm{DMSO}-d_{6}\right)$ $\delta=1.94-2.03\left(\mathrm{~m}, 4 \mathrm{H}, \mathrm{CH}_{2}\right), 2.92\left(\mathrm{~d}, J=6.0 \mathrm{~Hz}, 3 \mathrm{H}, \mathrm{CH}_{3}\right), 4.10$ (t, J=9.0 Hz, 2H, $\left.\mathrm{CH}_{2}\right), 8.13(\mathrm{~s}, \mathrm{H}, \mathrm{CH}), 8.16$ (s, H, NH), 8.71 $(\mathrm{s}, 1 \mathrm{H}, \mathrm{NH}), 10.37(\mathrm{~s}, 1 \mathrm{H}, \mathrm{NH}) \mathrm{ppm} ;{ }^{13} \mathrm{C}-\mathrm{NMR}(151 \mathrm{MHz}$, DMSO- $\left.d_{6}\right) \delta: 26.1,27.7,29.8,43.3,118.8,141.7,150.0,153.6$, 156.0, $168.6 \mathrm{ppm} ; \quad$ HR-MS-ESI: $m / z=283.0710 \quad\left([\mathrm{M}-\mathrm{H}]^{-}\right.$, Calcd), 283.0718 (Found).

4-(2-Chloro-6-ethylamino-9H-purin-9-yl)- $N$-hydroxybutanamide $\left(\mathbf{7} \mathbf{c}^{\prime}, \mathrm{C}_{11} \mathrm{H}_{15} \mathrm{ClN}_{6} \mathrm{O}_{2}\right)$

Isolated yield: $51 \%$; white powder; $\mathrm{mp}$ : $117-118^{\circ} \mathrm{C}$; IR (KBr): $v=1666$ (CO-acetyl), 2864 (CH-aliph), 3074 (CH-aryl), $3180(\mathrm{NH}), 3435(\mathrm{OH}) \mathrm{cm}^{-1}$; ${ }^{1} \mathrm{H}-\mathrm{NMR}\left(600 \mathrm{MHz}, \mathrm{DMSO}-d_{6}\right)$ $\delta=1.17\left(\mathrm{t}, J=9.0 \mathrm{~Hz}, 3 \mathrm{H}, \mathrm{CH}_{3}\right), 2.01\left(\mathrm{t}, J=6.0 \mathrm{~Hz}, 2 \mathrm{H}, \mathrm{CH}_{2}\right)$, $2.23\left(\mathrm{t}, J=9.0 \mathrm{~Hz}, 2 \mathrm{H}, \mathrm{CH}_{2}\right), 3.45\left(\mathrm{t}, J=6.0 \mathrm{~Hz}, 2 \mathrm{H}, \mathrm{CH}_{2}\right.$ ), $4.12\left(\mathrm{t}, J=9.0 \mathrm{~Hz}, 2 \mathrm{H}, \mathrm{CH}_{2}\right), 8.13(\mathrm{~s}, 1 \mathrm{H}, \mathrm{CH}), 8.25(\mathrm{~s}, 1 \mathrm{H}$, $\mathrm{NH}), 12.16(\mathrm{~s}, 1 \mathrm{H}, \mathrm{OH}) \mathrm{ppm} ;{ }^{13} \mathrm{C}-\mathrm{NMR}(151 \mathrm{MHz}, \mathrm{DMSO}-$ $\left.d_{6}\right) \delta=14.9,25.2,30.8,35.4,51.8,118.6,141.6,150.2,153.7$, 155.4, 173.1 ppm; HR-MS-ESI: $m / z=298.0945\left([\mathrm{M}]^{+}\right.$, Calcd), 298.0933 (Found).

4-(2-Chloro-6-propylamino-9H-purin-9-yl)- $N$-hydroxybutanamide ( $\left.7 \mathbf{d}^{\prime}, \mathrm{C}_{12} \mathrm{H}_{17} \mathrm{ClN}_{6} \mathrm{O}_{2}\right)$

Isolated yield: 46\%; white powder; $\mathrm{mp}: 194-195^{\circ} \mathrm{C}$; IR (KBr): $v=1606$ (CO-acetyl), 2912 (CH-aliph), 3305 (NH), $3400(\mathrm{OH}) \mathrm{cm}^{-1}$; ${ }^{1} \mathrm{H}-\mathrm{NMR}\left(600 \mathrm{MHz}, \mathrm{DMSO}-d_{6}\right) \delta=0.89(\mathrm{t}$, $\left.J=9.0 \mathrm{~Hz}, 3 \mathrm{H}, \mathrm{CH}_{3}\right), 1.60$ (q, $J=6.0 \mathrm{~Hz}, 2 \mathrm{H}, \mathrm{CH}_{2}$ ), 1.99-2.03 $\left(\mathrm{m}, 2 \mathrm{H}, \mathrm{CH}_{2}\right), 2.23\left(\mathrm{t}, J=9.0 \mathrm{~Hz}, 2 \mathrm{H}, \mathrm{CH}_{2}\right), 3.37-3.39(\mathrm{~m}$, $\left.2 \mathrm{H}, \mathrm{CH}_{2}\right), 4.12\left(\mathrm{t}, J=6.0 \mathrm{~Hz}, 2 \mathrm{H}, \mathrm{CH}_{2}\right), 8.14(\mathrm{~s}, 1 \mathrm{H}, \mathrm{CH}), 8.27$ $(\mathrm{s}, 1 \mathrm{H}, \mathrm{NH}), 12.17(\mathrm{~s}, 1 \mathrm{H}, \mathrm{OH}) \mathrm{ppm} ;{ }^{13} \mathrm{C}-\mathrm{NMR}(151 \mathrm{MHz}$, DMSO- $\left.d_{6}\right) \delta=11.8,22.6,25.3,31.2,42.3,43.1,118.6,141.6$, 150.2 , 153.6, 155.6, $174.2 \mathrm{ppm}$; HR-MS-ESI: $m / z=351.0739$ $\left([\mathrm{M}+\mathrm{K}]^{+}\right.$, Calcd), 351.0752 (Found).

4-(2-Chloro-6-phenylamino-9H-purin-9-yl)- $N$-hydroxybutanamide $\left(7 \mathbf{e}^{\prime}, \mathrm{C}_{15} \mathrm{H}_{15} \mathrm{ClN}_{6} \mathrm{O}_{2}\right)$

Isolated yield: 43\%; white powder; mp: $208-209^{\circ} \mathrm{C}$; IR (KBr): $v=1643$ (CO-acetyl), 2939 (CH-aliph), 3020 (CH-aryl), $3290(\mathrm{NH}), 3422(\mathrm{OH}) \mathrm{cm}^{-1}$; ${ }^{1} \mathrm{H}-\mathrm{NMR}\left(600 \mathrm{MHz}, \mathrm{DMSO}-d_{6}\right)$ $\delta=2.04-2.07\left(\mathrm{~m}, 2 \mathrm{H}, \mathrm{CH}_{2}\right), 2.26\left(\mathrm{t}, J=6.0 \mathrm{~Hz}, 2 \mathrm{H}, \mathrm{CH}_{2}\right), 4.20$ $\left(\mathrm{t}, J=6.0 \mathrm{~Hz}, 2 \mathrm{H}, \mathrm{CH}_{2}\right), 7.10(\mathrm{t}, J=9.0 \mathrm{~Hz}, 1 \mathrm{H}, \mathrm{ArH}), 7.36(\mathrm{t}$, $J=9.0 \mathrm{~Hz}, 2 \mathrm{H}, \mathrm{ArH}), 7.84(\mathrm{~d}, J=6.0 \mathrm{~Hz}, 2 \mathrm{H}, \mathrm{ArH}), 8.33$ (s, 1H, $\mathrm{CH}), 10.29$ (s, 1H, NH), $12.16(\mathrm{~s}, 1 \mathrm{H}, \mathrm{OH}) \mathrm{ppm} ;{ }^{13} \mathrm{C}-\mathrm{NMR}$ $\left(151 \mathrm{MHz}, \mathrm{DMSO}-d_{6}\right) \delta=24.9,28.9,43.7,119.3,121.2,121.7$, 123.9, 128.9, 129.0, 139.4, 151.3, 152.8, 175.0 ppm; HR-MSESI: $m / z=347.1023\left([\mathrm{M}+\mathrm{H}]^{+}\right.$, Calcd), 347.1018 (Found).

4-(2-Chloro-6-(4-methylphenyl)amino-9H-purin-9-yl)- $\mathrm{N}$ hydroxylbutanamide $\left(7 \mathbf{f}^{\prime}, \mathrm{C}_{16} \mathrm{H}_{17} \mathrm{ClN}_{6} \mathrm{O}_{2}\right)$

Isolated yield: $41 \%$; white powder; mp: $224-226^{\circ} \mathrm{C}$; IR (KBr): $v=1618$ (CO-acetyl), 2889 (CH-aliph), $3254(\mathrm{NH})$, $3365(\mathrm{OH}) \mathrm{cm}^{-1}$; ${ }^{1} \mathrm{H}-\mathrm{NMR}\left(600 \mathrm{MHz}, \mathrm{DMSO}-d_{6}\right) \quad \delta=2.04$ (t, $\left.J=6.0 \mathrm{~Hz}, 2 \mathrm{H}, \mathrm{CH}_{2}\right), 2.18\left(\mathrm{~s}, 2 \mathrm{H}, \mathrm{CH}_{2}\right), 2.28(\mathrm{~d}, J=12 \mathrm{~Hz}$, $\left.3 \mathrm{H}, \mathrm{CH}_{3}\right), 4.19\left(\mathrm{t}, J=6.0 \mathrm{~Hz}, 2 \mathrm{H}, \mathrm{CH}_{2}\right), 7.17(\mathrm{~d}, J=6.0 \mathrm{~Hz}, 2 \mathrm{H}$, ArH), 7.69 (d, J=12 Hz, 2H, ArH), 8.31 (s, 1H, CH), 10.20 (s, $1 \mathrm{H}, \mathrm{NH}) \mathrm{ppm} ;{ }^{13} \mathrm{C}-\mathrm{NMR}\left(151 \mathrm{MHz}, \mathrm{DMSO}-d_{6}\right) \delta=25.2,30.8$, 49.1, 55.7, 114.3, 119.1, 123.7, 132.2, 142.5, 151.2, 153.1, 156.2, 173.0 ppm; HR-MS-ESI: $m / z=361.1180\left([\mathrm{M}+\mathrm{H}]^{+}, \quad\right.$ Calcd $)$, 361.1167 (Found). 
4-(2-Chloro-6-(4-methoxyphenyl)amino-9H-purin-9-yl)- $\mathrm{N}$ hydroxylbutanamide $\left(\mathbf{7 g}^{\prime}, \mathrm{C}_{16} \mathrm{H}_{17} \mathrm{ClN}_{6} \mathrm{O}_{3}\right)$

Isolated yield: $52 \%$; light yellow powder; $\mathrm{mp}$ : $90-91{ }^{\circ} \mathrm{C}$; IR (KBr): $v=1622$ (CO-acetyl), 3050 (CH-aryl), 2954 (CHaliph), $3258(\mathrm{NH}), 3566(\mathrm{OH}) \mathrm{cm}^{-1}$; ${ }^{1} \mathrm{H}-\mathrm{NMR}(600 \mathrm{MHz}$, DMSO- $\left.d_{6}\right) \delta=2.09\left(\mathrm{t}, J=9.0 \mathrm{~Hz}, 2 \mathrm{H}, \mathrm{CH}_{2}\right), 2.36(\mathrm{t}, J=6.0 \mathrm{~Hz}$, $\left.2 \mathrm{H}, \mathrm{CH}_{2}\right), 3.56\left(\mathrm{~s}, 3 \mathrm{H}, \mathrm{CH}_{3}\right), 4.21\left(\mathrm{t}, J=6.0 \mathrm{~Hz}, 2 \mathrm{H}, \mathrm{CH}_{2}\right)$, 7.10 (t, $J=9.0 \mathrm{~Hz}, 1 \mathrm{H}, \mathrm{NH}), 7.35-7.36(\mathrm{~m}, 2 \mathrm{H}, \mathrm{ArH}), 7.84$ (d, $J=6.0 \mathrm{~Hz}, 2 \mathrm{H}), 8.32(\mathrm{~s}, 1 \mathrm{H}, \mathrm{CH}), 10.26(\mathrm{~s}, 1 \mathrm{H}, \mathrm{NH}) \mathrm{ppm}$; ${ }^{13} \mathrm{C}-\mathrm{NMR}\left(151 \mathrm{MHz}, \mathrm{DMSO}-d_{6}\right) \delta=25.2,30.8,51.9,55.7,114.3$, $119.1,123.6,132.2,142.5,151.2,153.0,156.2,173.0$ ppm; HRMS-ESI: $m / z=376.1051$ ([M] $]^{+}$, Calcd), 376.1053 (Found).

4-(2-Chloro-6-(4-chlorophenyl)amino-9H-purin-9-yl)- $\mathrm{N}$ hydroxybutanamide $\left(7 \mathbf{h}^{\prime}, \mathrm{C}_{15} \mathrm{H}_{14} \mathrm{Cl}_{2} \mathrm{~N}_{6} \mathrm{O}_{2}\right)$

Isolated yield: $38 \%$; white powder; $\mathrm{mp}:>300^{\circ} \mathrm{C}$; IR (KBr): $v=1635$ (CO-acetyl), 2851 (CH-aliph), 2930 (CH-aryl), 3173 $(\mathrm{NH}), 3433(\mathrm{OH}) \mathrm{cm}^{-1}$; ${ }^{1} \mathrm{H}-\mathrm{NMR}\left(600 \mathrm{MHz}, \mathrm{DMSO}-d_{6}\right)$ $\delta=2.06\left(\mathrm{t}, J=9.0 \mathrm{~Hz}, 2 \mathrm{H}, \mathrm{CH}_{2}\right), 2.26\left(\mathrm{t}, J=6.0 \mathrm{~Hz}, 2 \mathrm{H}, \mathrm{CH}_{2}\right)$, $4.20\left(\mathrm{t}, J=9.0 \mathrm{~Hz}, 2 \mathrm{H}, \mathrm{CH}_{2}\right), 7.42(\mathrm{~d}, J=6.0 \mathrm{~Hz}, 2 \mathrm{H}, \mathrm{ArH})$, $7.89(\mathrm{~d}, J=6.0 \mathrm{~Hz}, 2 \mathrm{H}, \mathrm{ArH}), 8.35(\mathrm{~s}, 1 \mathrm{H}, \mathrm{CH}), 10.43(\mathrm{~s}, 1 \mathrm{H}$, $\mathrm{NH}) \mathrm{ppm} ;{ }^{13} \mathrm{C}-\mathrm{NMR}\left(151 \mathrm{MHz}, \mathrm{DMSO}-d_{6}\right) \delta=25.5,31.8,43.4$, $119.4,123.1,127.6,128.9,138.4,143.1,151.5,152.6,165.6$, 174.8 ppm; HR-MS-ESI: $m / z=379.0477\left([\mathrm{M}-\mathrm{H}]^{-}, \quad\right.$ Calcd $)$, 379.0475 (Found).

4-(2-Chloro-6-(4-hydroxyphenyl)amino-9H-purin-9-yl)- $\mathrm{N}$ hydroxybutanamide $\left(7 \mathbf{i}^{\prime}, \mathrm{C}_{15} \mathrm{H}_{15} \mathrm{ClN}_{6} \mathrm{O}_{3}\right)$

Isolated yield: $41 \%$; light yellow powder; $\mathrm{mp}$ : $230-232^{\circ} \mathrm{C}$; IR (KBr): $v=1673$ (CO-acetyl), 2741 (CH-aliph), 2929 (CHaryl), $3119(\mathrm{NH}), 3256(\mathrm{OH}) \mathrm{cm}^{-1}$; ${ }^{1} \mathrm{H}-\mathrm{NMR}(600 \mathrm{MHz}$, DMSO- $\left.d_{6}\right) \delta=1.99-2.05\left(\mathrm{~m}, 2 \mathrm{H}, \mathrm{CH}_{2}\right), 2.26(\mathrm{t}, J=9.0 \mathrm{~Hz}$, $\left.2 \mathrm{H}, \mathrm{CH}_{2}\right), 4.17\left(\mathrm{t}, J=6.0 \mathrm{~Hz}, 2 \mathrm{H}, \mathrm{CH}_{2}\right), 6.75(\mathrm{t}, J=6.0 \mathrm{~Hz}, 2 \mathrm{H}$, ArH), 7.53 (d, J=6.0 Hz, 2H, ArH), 8.26 (s, 1H, CH), 9.30 (s, $1 \mathrm{H}, \mathrm{NH}), 10.01(\mathrm{~s}, 1 \mathrm{H}, \mathrm{NH}), 12.17(\mathrm{~s}, 1 \mathrm{H}, \mathrm{OH}) \mathrm{ppm} ;{ }^{13} \mathrm{C}-\mathrm{NMR}$ $\left(151 \mathrm{MHz}, \mathrm{DMSO}-d_{6}\right) \delta=25.3,31.3,60.3,115.5,119.0,124.1$, $126.5,130.6,142.3,151.1,153.0,154.5,170.9,174.2$ ppm; HRMS-ESI: $m / z=362.0894$ ([M] $]^{+}$, Calcd), 362.0891 (Found).

8-(2,6-Dichloro-9H-purin-9-yl)- $N$-hydroxyoctanamide $\mathrm{C}_{13} \mathrm{H}_{17} \mathrm{Cl}_{2} \mathrm{~N}_{5} \mathrm{O}_{2}$ )

Isolated yield: $56 \%$; mp: $76-78^{\circ} \mathrm{C}$; IR (KBr): $v=1604$ (CO-acetyl), 2951 (CH-aliph), $3113(\mathrm{NH}), 3452(\mathrm{OH}) \mathrm{cm}^{-1}$; ${ }^{1} \mathrm{H}-\mathrm{NMR}\left(600 \mathrm{MHz}, \mathrm{DMSO}-d_{6}\right) \delta=1.22-1.28\left(\mathrm{~m}, 6 \mathrm{H}, \mathrm{CH}_{2}\right)$, $1.46\left(\mathrm{t}, J=6.0 \mathrm{~Hz}, 2 \mathrm{H}, \mathrm{CH}_{2}\right), 1.77\left(\mathrm{t}, J=6.0 \mathrm{~Hz}, 2 \mathrm{H}, \mathrm{CH}_{2}\right), 2.16$ $\left(\mathrm{t}, J=6.0 \mathrm{~Hz}, 2 \mathrm{H}, \mathrm{CH}_{2}\right), 4.12\left(\mathrm{t}, J=6.0 \mathrm{~Hz}, 2 \mathrm{H}, \mathrm{CH}_{2}\right), 8.08$ $(\mathrm{s}, 1 \mathrm{H}, \mathrm{CH}), 12.23(\mathrm{~s}, 1 \mathrm{H}, \mathrm{OH}) \mathrm{ppm} ;{ }^{13} \mathrm{C}-\mathrm{NMR}(151 \mathrm{MHz}$, DMSO- $\left.d_{6}\right) \delta=15.0,25.2,30.8,35.4,42.9,51.8,118.7,141.6$, 150.3, 153.7, 155.4, $173.0 \mathrm{ppm}$; HR-MS-ESI: $\mathrm{m} / \mathrm{z}=346.0838$ $\left([\mathrm{M}+\mathrm{H}]^{+}\right.$, Calcd), 346.0839 (Found).

8-(2-Chloro-6-propylamino-9H-purin-9-yl)- $N$-hydroxyoctanamide $\left(7 \mathbf{k}^{\prime}, \mathrm{C}_{16} \mathrm{H}_{25} \mathrm{ClN}_{6} \mathrm{O}_{2}\right)$

Isolated yield: $41 \%$; white powder; $\mathrm{mp}: 110-111^{\circ} \mathrm{C}$; IR (KBr): $v=1635$ (CO-acetyl), 2895 (CH-aliph), 2987 (CH-aryl), $3254(\mathrm{NH}), 3360(\mathrm{OH}) \mathrm{cm}^{-1}$; ${ }^{1} \mathrm{H}-\mathrm{NMR}\left(600 \mathrm{MHz}, \mathrm{DMSO}-d_{6}\right)$ $\delta=0.89\left(\mathrm{t}, J=6.0 \mathrm{~Hz}, 3 \mathrm{H}, \mathrm{CH}_{3}\right), 1.22-1.29\left(\mathrm{~m}, 6 \mathrm{H}, \mathrm{CH}_{2}\right), 1.45$ (t, $\left.J=9.0 \mathrm{~Hz}, 2 \mathrm{H}, \mathrm{CH}_{2}\right), 1.59$ (q, $\left.J=6.0 \mathrm{~Hz}, 2 \mathrm{H}, \mathrm{CH}_{2}\right), 1.76$ (t, $\left.J=9.0 \mathrm{~Hz}, 2 \mathrm{H}, \mathrm{CH}_{2}\right), 2.17\left(\mathrm{t}, J=6.0 \mathrm{~Hz}, 2 \mathrm{H}, \mathrm{CH}_{2}\right), 3.37$ (q, $\left.J=6.0 \mathrm{~Hz}, 2 \mathrm{H}, \mathrm{CH}_{2}\right), 3.81(\mathrm{~s}, 1 \mathrm{H}, \mathrm{NH}), 4.08(\mathrm{t}, J=6.0 \mathrm{~Hz}, 2 \mathrm{H}$, $\left.\mathrm{CH}_{2}\right), 8.15(\mathrm{~s}, 1 \mathrm{H}, \mathrm{CH}), 8.26(\mathrm{~s}, 1 \mathrm{H}, \mathrm{NH}), 11.97(\mathrm{~s}, 1 \mathrm{H}, \mathrm{OH})$ ppm; ${ }^{13} \mathrm{C}-\mathrm{NMR}$ (151 MHz, DMSO- $\left.d_{6}\right) \quad \delta=11.8,22.6,24.9$, 26.3, 28.9, 34.1, 42.3, 43.5, 118.6, 141.6, 150.2, 153.6, 155.6, 174.9 ppm; HR-MS-ESI: $m / z=369.1806\left([\mathrm{M}+\mathrm{H}]^{+}, \quad\right.$ Calcd $)$, 369.1807 (Found).
8-(2-Chloro-6-phenylamino-9H-purin-9-yl)- $N$-hydroxyoctanamide $\left(7 \mathbf{l}^{\prime}, \mathrm{C}_{19} \mathrm{H}_{23} \mathrm{ClN}_{6} \mathrm{O}_{2}\right)$

Isolated yield: 43\%; white powder; $\mathrm{mp}: 158-160^{\circ} \mathrm{C}$; IR (KBr): $v=1670$ (CO-acetyl), 2989 (CH-aliph), 3080 (CH-aryl), $3223(\mathrm{NH}), 3395(\mathrm{OH}) \mathrm{cm}^{-1}$; ${ }^{1} \mathrm{H}-\mathrm{NMR}(600 \mathrm{MHz}$, DMSO$\left.d_{6}\right) \delta=1.24-1.31\left(\mathrm{~m}, 6 \mathrm{H}, \mathrm{CH}_{2}\right), 1.47\left(\mathrm{t}, J=6.0 \mathrm{~Hz}, 2 \mathrm{H}, \mathrm{CH}_{2}\right)$, $1.81\left(\mathrm{t}, J=6.0 \mathrm{~Hz}, 2 \mathrm{H}, \mathrm{CH}_{2}\right), 2.18\left(\mathrm{t}, J=6.0 \mathrm{~Hz}, 2 \mathrm{H}, \mathrm{CH}_{2}\right), 4.16$ $\left(\mathrm{t}, J=9.0 \mathrm{~Hz}, 2 \mathrm{H}, \mathrm{CH}_{2}\right), 7.10(\mathrm{t}, J=9.0 \mathrm{~Hz}, 1 \mathrm{H}, \mathrm{ArH}), 7.36(\mathrm{t}$, $J=9.0 \mathrm{~Hz}, 2 \mathrm{H}, \mathrm{ArH}), 7.84$ (d, $J=6.0 \mathrm{~Hz}, 2 \mathrm{H}, \mathrm{ArH}), 8.35$ (s, 1H, $\mathrm{CH}), 9.86(\mathrm{~s}, 1 \mathrm{H}, \mathrm{NH}), 10.28(\mathrm{~s}, 1 \mathrm{H}, \mathrm{NH}), 11.98(\mathrm{~s}, 1 \mathrm{H}, \mathrm{OH})$ ppm; ${ }^{13} \mathrm{C}-\mathrm{NMR}\left(151 \mathrm{MHz}, \mathrm{DMSO}-d_{6}\right) \delta=24.9,26.3,28.6,28.9$, 29.6, 34.1, 43.7, 119.3, 121.2, 121.7, 123.9, 128.9, 129.0, 139.4, 151.3, 152.9, 174.9 ppm; HR-MS-ESI: $m / z=402.1571\left([\mathrm{M}]^{+}\right.$, Calcd), 402.1575 (Found).

8-(2-Chloro-6-(4-methylphenyl)amino-9H-purin-9-yl)- $\mathrm{N}$ hydroxyoctanamide $\left(7 \mathbf{m}^{\prime}, \mathrm{C}_{20} \mathrm{H}_{25} \mathrm{ClN}_{6} \mathrm{O}_{2}\right)$

Isolated yield: $46 \%$; white powder; $\mathrm{mp}: 140-142^{\circ} \mathrm{C}$; IR (KBr): $v=1658$ (CO-acetyl), 2932 (CH-aliph), 3024 (CH-aryl), $3256(\mathrm{NH}), 3332(\mathrm{OH}) \mathrm{cm}^{-1}$; ${ }^{1} \mathrm{H}-\mathrm{NMR}(600 \mathrm{MHz}, \mathrm{DMSO}-$ $\left.d_{6}\right) \delta=1.24-1.30\left(\mathrm{~m}, 6 \mathrm{H}, \mathrm{CH}_{2}\right), 1.47\left(\mathrm{t}, J=6.0 \mathrm{~Hz}, 2 \mathrm{H}, \mathrm{CH}_{2}\right)$, $1.79\left(\mathrm{t}, J=9.0 \mathrm{~Hz}, 2 \mathrm{H}, \mathrm{CH}_{2}\right), 2.17-2.18\left(\mathrm{~m}, 2 \mathrm{H}, \mathrm{CH}_{2}\right), 2.28(\mathrm{~d}$, $\left.J=12.0 \mathrm{~Hz}, 3 \mathrm{H}, \mathrm{CH}_{3}\right), 4.15\left(\mathrm{t}, J=9.0 \mathrm{~Hz}, 2 \mathrm{H}, \mathrm{CH}_{2}\right), 7.17(\mathrm{~d}$, $J=6.0 \mathrm{~Hz}, 2 \mathrm{H}, \mathrm{ArH}), 7.69$ (d, $J=12.0 \mathrm{~Hz}, 2 \mathrm{H}, \mathrm{ArH}), 8.32$ (s, $1 \mathrm{H}, \mathrm{CH}), 10.18$ (s, 1H, NH), $11.96(\mathrm{~s}, 1 \mathrm{H}, \mathrm{OH}) \mathrm{ppm} ;{ }^{13} \mathrm{C}-\mathrm{NMR}$ $\left(151 \mathrm{MHz}, \mathrm{DMSO}-d_{6}\right) \quad \delta=24.9,26.3,28.6,28.9,29.9,34.1$, 43.7, 55.7, 114.3, 119.0, 123.7, 132.2, 142.5, 151.1, 153.1, 156.2, 174.9 ppm; HR-MS-ESI: $m / z=416.1728$ ([M] $]^{+}$, Calcd), 416.1725 (Found).

8-(2-Chloro-6-(4-methoxyphenyl)amino-9H-purin-9-yl)- $\mathrm{N}$ hydroxyoctanamide $\left(7 \mathbf{n}^{\prime}, \mathrm{C}_{20} \mathrm{H}_{25} \mathrm{ClN}_{6} \mathrm{O}_{3}\right)$

Isolated yield: $40 \%$; white powder; $\mathrm{mp}: 210-212^{\circ} \mathrm{C}$; IR (KBr): $v=1643$ (CO-acetyl), 2895 (CH-aliph), 3011 (CH-aryl), $3300(\mathrm{NH}), 3516(\mathrm{OH}) \mathrm{cm}^{-1} ;{ }^{1} \mathrm{H}-\mathrm{NMR}\left(600 \mathrm{MHz}, \mathrm{DMSO}-d_{6}\right)$ $\delta=1.24-1.30\left(\mathrm{~m}, 6 \mathrm{H}, \mathrm{CH}_{2}\right), 1.47\left(\mathrm{t}, J=6.0 \mathrm{~Hz}, 2 \mathrm{H}, \mathrm{CH}_{2}\right), 1.79$ (t, J=6.0 Hz, 2H, $\left.\mathrm{CH}_{2}\right), 2.18\left(\mathrm{t}, J=6.0 \mathrm{~Hz}, 2 \mathrm{H}, \mathrm{CH}_{2}\right), 3.76$ (s, $\left.3 \mathrm{H}, \mathrm{CH}_{3}\right), 4.14\left(\mathrm{t}, J=6.0 \mathrm{~Hz}, 2 \mathrm{H}, \mathrm{CH}_{2}\right), 6.95(\mathrm{~d}, J=6.0 \mathrm{~Hz}, 2 \mathrm{H}$, ArH), 7.68 (d, J=6.0 Hz, 2H, ArH), 8.30 (s, 1H, CH), 10.14 (s, $1 \mathrm{H}, \mathrm{NH}), 11.98$ (s, 1H, OH) ppm; ${ }^{13} \mathrm{C}-\mathrm{NMR}$ (151 MHz, DMSO$\left.d_{6}\right) \delta=24.9,26.3,28.6,28.9,29.7,34.1,43.7,55.8,114.3,119.0$, $123.7,132.2,142.5,151.1,152.9,153.1,156.2$, 175.0 ppm; HRMS-ESI: $m / z=432.1677$ ([M] $]^{+}$Calcd), 432.1687 (Found).

8-(2-Chloro-6-(4-chlorophenyl)amino-9H-purin-9-yl)- $\mathrm{N}$ hydroxyoctanamide $\left(\mathbf{7 o}^{\prime}, \mathrm{C}_{19} \mathrm{H}_{22} \mathrm{Cl}_{2} \mathrm{~N}_{6} \mathrm{O}_{2}\right)$

Isolated yield: $32 \%$; white powder; mp: $190-192^{\circ} \mathrm{C}$; IR (KBr): $v=1636$ (CO-acetyl), 2916 (CH-aliph), 3061 (CH-aryl), $3138(\mathrm{NH}), 3342(\mathrm{OH}) \mathrm{cm}^{-1}$; ${ }^{1} \mathrm{H}-\mathrm{NMR}(600 \mathrm{MHz}$, DMSO$\left.d_{6}\right): \delta=1.24-1.30\left(\mathrm{~m}, 6 \mathrm{H}, \mathrm{CH}_{2}\right), 1.47\left(\mathrm{t}, J=6.0 \mathrm{~Hz}, 2 \mathrm{H}, \mathrm{CH}_{2}\right)$, $1.81\left(\mathrm{t}, J=6.0 \mathrm{~Hz}, 2 \mathrm{H}, \mathrm{CH}_{2}\right), 2.18\left(\mathrm{t}, J=9.0 \mathrm{~Hz}, 2 \mathrm{H}, \mathrm{CH}_{2}\right), 4.16$ (t, $\left.J=6.0 \mathrm{~Hz}, 2 \mathrm{H}, \mathrm{CH}_{2}\right), 7.42(\mathrm{~d}, J=12 \mathrm{~Hz}, 2 \mathrm{H}, \mathrm{ArH}), 7.88$ (d, $J=12 \mathrm{~Hz}, 2 \mathrm{H}, \mathrm{ArH}), 8.37$ (s, 1H, CH), 10.42 (s, 2H, NH), 11.97 $(\mathrm{s}, 2 \mathrm{H}, \mathrm{OH}) \mathrm{ppm} ;{ }^{13} \mathrm{C}-\mathrm{NMR}\left(151 \mathrm{MHz}, \mathrm{DMSO}-d_{6}\right) \delta=24.9$, 26.3, 28.6, 28.9, 29.6, 34.2, 49.1, 119.4, 122.6, 123.1, 127.6, 128.9, 138.4, 143.1, 151.5, 152.7, 174.9 ppm; HR-MS-ESI: $m / z=436.1181$ ([M] $]^{+}$, Calcd), IR (KBr): $v=436.1195$ (Found).

8-(2-Chloro-6-(4-hydroxyphenyl)amino-9H-purin-9-yl)- $\mathrm{N}$ hydroxyoctanamide $\left(7 \mathbf{p}^{\prime}, \mathrm{C}_{19} \mathrm{H}_{23} \mathrm{ClN}_{6} \mathrm{O}_{3}\right)$

Isolated yield: $35 \%$; white powder; $\mathrm{mp}: 230-232^{\circ} \mathrm{C}$. IR (KBr): $v=1636$ (CO-acetyl), 2972 (CH-aliph), 3060 (CH-aryl), $3240(\mathrm{OH}) \mathrm{cm}^{-1}$; ${ }^{1} \mathrm{H}-\mathrm{NMR}\left(600 \mathrm{MHz}, \mathrm{DMSO}-d_{6}\right): \delta=1.23-1.30$ $\left(\mathrm{m}, 6 \mathrm{H}, \mathrm{CH}_{2}\right), 1.47$ (t, $\left.J=6.0 \mathrm{~Hz}, 2 \mathrm{H}, \mathrm{CH}_{2}\right), 1.79$ (t, $J=9.0 \mathrm{~Hz}$, $\left.2 \mathrm{H}, \mathrm{CH}_{2}\right), 2.18\left(\mathrm{t}, J=6.0 \mathrm{~Hz}, 2 \mathrm{H}, \mathrm{CH}_{2}\right), 4.13(\mathrm{t}, J=9.0 \mathrm{~Hz}, 2 \mathrm{H}$, 
$\left.\mathrm{CH}_{2}\right), 6.75(\mathrm{~d}, J=6.0 \mathrm{~Hz}, 2 \mathrm{H}, \mathrm{ArH}), 7.51$ (d, $J=12.0 \mathrm{~Hz}, 2 \mathrm{H}$, ArH), 8.27 (s, 1H, CH), 9.29 (s, 1H, NH), 10.00 (s, 1H, NH), 11.97 (s, $1 \mathrm{H}, \mathrm{OH}) \mathrm{ppm} ;{ }^{13} \mathrm{C}-\mathrm{NMR}\left(151 \mathrm{MHz}, \mathrm{DMSO}-d_{6}\right)$ : $\delta=24.9,26.3,28.6,28.9,29.7,34.2,43.7,115.5,119.0,124.0$, $130.6,142.3,151.0,153.0,153.2,154.4,175.0$ ppm; HR-MSESI: $m / z=441.1418\left([\mathrm{M}+\mathrm{Na}]^{+}\right.$, Calcd), 441.1405 (Found).

In Vitro HDAC Assay The HDAC Colorimetric Assay/ Drug Discovery Kit was bought from Enzo Biochem Inc. The reagents were prepared for assay following the instructions. On the 96-well plate, HDACs $(5 \mu \mathrm{L} /$ well $)$ were incubated at $37^{\circ} \mathrm{C}$ with $10 \mu \mathrm{L}$ of various concentrations of inhibitors and $25 \mu \mathrm{L}$ of substrate. After reacting for $30 \mathrm{~min}$, Color de Lys Developer $(50 \mu \mathrm{L} /$ well) was added. The ultraviolet absorption of the wells was measured on a microtiter-plate reader (BIORAD: model 680 ) at $405 \mathrm{~nm}$ after $15 \mathrm{~min}$. The inhibition ratios were calculated from the optical density (OD) values. Finally, the $\mathrm{IC}_{50}$ values were determined using a regression analysis of the concentration/inhibition data.

MTT Assay Antitumor activity in vitro was determined by the improved MTT assay. ${ }^{32)}$ The HCT116, K562 cell lines were cultured in RPMI1640 medium containing 10\% heatinactivated fetal bovine serum (FBS) at $37^{\circ} \mathrm{C}$ in $5 \% \mathrm{CO}_{2}$ humidified incubator. The logarithmic growth phase cells were collected for experiments. Tumor cells $\left(2.0 \times 10^{5}\right.$ cells $\left./ \mathrm{mL}\right)$ were inoculated in $96-$ well culture plates $(90 \mu \mathrm{L} /$ well). Then $10 \mu \mathrm{L}$ of culture medium containing synthetic compound of various concentrations was added to the wells, then the cells were incubated for $48 \mathrm{~h}$ at $37^{\circ} \mathrm{C}$ in $5 \% \mathrm{CO}_{2}$ atmosphere. Twenty microliters of MTT was added at a final concentration of $5 \mathrm{mg} / \mathrm{mL}$ and after $4 \mathrm{~h}$ incubation, $100 \mu \mathrm{L}$ Triple solution $(10 \%$ sodium dodecyl sulfate (SDS), $5 \%$ isobutanol, $0.01 \mathrm{~mol} / \mathrm{L} \mathrm{HCl}$ ) were added. The suspension was placed in the dark incubator at $37^{\circ} \mathrm{C}$ overnight and the optical density was measured at $570 \mathrm{~nm}$, then the $\mathrm{IC}_{50}$ values were calculated.

Western Blot Analysis K562 and HCT116 cells were treated with $0.1 \%$ DMSO or indicated test compound at $10 \mu \mathrm{M}$ in RPMI 1640 supplemented with $10 \%$ FBS for $24 \mathrm{~h}$. For does-dependency tests of $\mathbf{7 \mathbf { m } ^ { \prime }}$ and SAHA, K562 and HCT116 cells were treated with $0.1 \%$ DMSO or indicated test compound at $0.03,0.3,1,3,10 \mu \mathrm{M}$ for $24 \mathrm{~h}$. The cells were then collected in icecold lysis buffer $[10 \mathrm{mmol} / \mathrm{L}$ Tris $-\mathrm{HCl}(\mathrm{pH}$ 7.4), $150 \mathrm{mmol} / \mathrm{L} \mathrm{NaCl}, 1 \mathrm{mmol} / \mathrm{L}$ glycol bis(2-aminoethyl ether)- $N, N, N^{\prime}, N^{\prime}$-tetraacetic acid (EGTA), $1 \mathrm{mmol} / \mathrm{L}$ phenylmethylsulfonyl fluoride, $10 \mathrm{mg} / \mathrm{mL}$ aprotinin, $10 \mathrm{mg} / \mathrm{mL}$ leupeptin, $1 \mathrm{~mm}$ sodium orthovanadate, $1 \mathrm{~mm} \mathrm{NaF}$, and $1 \%$ Triton $\mathrm{X}-100]$ and sonicated. Protein concentrations in the resultant lysates were determined by Bicinchoninic Acid (BCA) protein assay. The protein lysates, containing the same amount of proteins, were subjected to $10 \%$ SDS-polyacrylamide gel electrophoresis. The proteins were then transferred to a polyvinylidene difluoride (PVDF) membrane (Millipore, Bellerica, MA, U.S.A.). After $1 \mathrm{~h}$ incubation at room temperature in 5\% nonfat milk in phosphate buffered saline (PBS), transblotted membranewas washed twice with tris-buffered saline containing $0.1 \%$ Tween 20 (TBST). Membrane was then immunoblotted with primary antibodies against histone H3 (DIH2), acetylated histone H3 (Lys 9) (C5BII, Cell Signaling Technologies), $\beta$-actin (7D2C10, Proteintech Group, Inc.). Detection was performed with anti-rabbit horseradish peroxidase-conjugated secondary antibodies (ZSBG-BIO, China). The membranes were washed three times $10 \mathrm{~min}$ each in TBS-T, for detection, the membranes were saturated with enhanced chemiluminescence mixture for $1 \mathrm{~min}$, and chemiluminescence was viewed by autography using pre-flashed X-ray film (FUJIFILM, Tokyo, Japan) for $300 \mathrm{~s}$.

Docking Studies Docking studies were performed using a free Autodock 4.0. ${ }^{39)}$ The three-dimensional structures of the proposed compounds were constructed and energy minimizations were performed with the Chem-Draw/Chem3D. Docking studies were performed as described in our previous papers. ${ }^{35)}$ The complexes pictures were rendered employing the UCSF Chimera software. ${ }^{40)}$

Acknowledgments This work was supported by the National Nature Science Fundation of China (Grant No. 81360469) and the program of Science and Technology Project of Jiangxi Province (20122BBG70094-2). The authors also thank Center of Analysis and Testing of Nanchang University for assistance with the MS and NMR testing of compounds.

Conflict of Interest The authors declare no conflict of interest.

Supplementary Materials The online version of this article contains supplementary materials.

\section{References}

1) Cress W. D., Seto E., J. Cell. Physiol., 184, 1-16 (2000).

2) Manal M., Chandrasekar M. J. N., Priya J. G., Nanjan M. J., Bioorg. Chem., 67, 18-42 (2016).

3) Bolden J. E., Peart M. J., Johnstone R. W., Nat. Rev. Drug Discov., 5, 769-784 (2006).

4) Gregoretti I., Lee Y. M., Goodson H. V., J. Mol. Biol., 338, 17-31 (2004).

5) Dokmanovic M., Clarke C., Marks P. A., Mol. Cancer Res., 5, 981-989 (2007)

6) Ropero S., Esteller M., Mol. Oncol., 1, 19-25 (2007).

7) Ruijter A. J., Gennip A. H., Caron H. N., Kemp S., Kuilenburg A. B., Biochem. J., 370, 737-749 (2003).

8) Witt O., Hedwig E. D., Milde T., Oehme I., Cancer Lett., 277, 8-21 (2009).

9) Marks P. A., BBA-Biomembranes, 1799, 717-725 (2010).

10) Glozak M. A., Sengupta N., Zhang X. H., E. Seto. Gene, 363, 15-23 (2005).

11) Caputi F. F., Palmisano M., D’Addario C., Candeletti S., Romualdi P., Drug Alcohol Depend., 155, 68-75 (2015).

12) Paris M., Porcelloni M., Binaschi M., Fattori D., J. Med. Chem., 51, 1505-1529 (2008).

13) Marks P. A., Oncogene, 26, 1351-1356 (2007).

14) Barbarotta L., Hurley K., J. Adv. Pract. Oncol., 6, 22-36 (2015).

15) Qian X., Ara G., Mills E., LaRochelle W. J., Lichenstein H. S., Jeffers M., Int. J. Cancer, 122, 1400-1410 (2008).

16) Laubach J. P., Moreau P., San-Miguel J. F., Richardson P. G., Clin. Cancer Res., 21, 4767-4773 (2015).

17) Rajak H., Singh A., Raghuwanshi K., Kumar R., Dewangan P. K. Veeraswamy R., Sharma P. C., Dixit A., Mishra P., Curr. Med. Chem., 21, 2642-2644 (2014).

18) Bolden J. E., Peart M. J., Johnstone R. W., Nat. Rev. Drug Discov., 5, 769-784 (2006).

19) Zhang Y. J., Feng J. H., Jia Y. P., Xu Y. Y., Liu C., Fang H., Xu W., Eur. J. Med. Chem., 46, 5387-5397 (2011).

20) Azimi F., Esmaeilzadeh A., Ramazani A., Pharmacol. Res., 102, 61-62 (2015).

21) Köchling J., Rott Y., Arndt S., Marschke C., Schmidt M., Wittig B. Kalies K., Westermann J., Henze G., Vaccine, 30, 5949-5955 (2012). 
22) Hoffmann M., Chrzanowska M., Hermann T., Ryehlewski J., J. Med. Chem., 48, 4482-4486 (2005).

23) Johnson S. A., Thomas W., Hematol. Oncol., 18, 141-153 (2000).

24) Ghanem H., Kantarjian H., Ohanian M., Jabbour E., Leuk. Lymphoma, 54, 688-698 (2013).

25) DeAngelo D. J., Hematol. Oncol. Clin. North Am., 23, 1121-1135, vii-viii (2009).

26) Harrison L. R. E., Ottley C. J., Pearson D. G., Roche C., Wedge S. R., Dolan M. E., Newell D. R., Tilby M. J., Biochem. Pharmacol., 77, 1586-1592 (2009).

27) Hsieh W. S., Soo R., Peh B. K., Loh T., Dong D., Soh D., Wong L. S., Green S., Chiao J., Cui C. Y., Lai Y. F., Lee S. C., Mow B., Soong R., Salto-Tellez M., Goh B. C., Clin. Cancer Res., 15, 1435-1442 (2009).

28) MacCallum D. E., Melville J., Frame S., Watt K., Anderson S., Gianella-Borradori A., Lane D. P., Green S. R., Cancer Res., 65, 5399-5407 (2005)

29) Mohapatra S., Chu B., Zhao X., Pledger W. J., Cancer Res., 65, 7717-7723 (2005).

30) Chen R., Keating M. J., Gandhi V., Plunkett W., Blood, 106, $2513-$ 2519 (2005).

31) Miller T. A., Witter D. J., Belvedere S., J. Med. Chem., 46, $5097-$ $5116(2003)$

32) Mai X., Lu X. S., Xia H. Y., Cao Y. S., Liao Y. J., Lv X. L., Chem.
Pharm. Bull., 58, 94-97 (2010).

33) Xia H. X., Mai X., Mai B., Zhong W. J., Liu C., Liao Y. J., Feng L. H., Asian J. Chem., 25, 10043-10049 (2013).

34) Reng F., Zhong Y., Mai X., Liao Y. J., Liu C., Feng L. H., Sun W., Zen W. B., Liu W. M., Liu J., Jin N., Chem. Pharm. Bull., 62, 898-905 (2014)

35) Lun J., Zhang K., Mai X., Wei J., Liao Y. J., Zhong Y., Liu Y., Feng L. H., Liu C., Med. Chem., 11, 37-47 (2015).

36) Lauffer B. E. L., Mintzer R., Fong R., Mukund S., Tam C., Zilberleyb I., Flicke B., Ritscher A., Fedorowicz G., Vallero R., Ortwine D. F., Gunzner J., Modrusan Z., Neumann L., Koth C. M., Lupardus P. J., Kaminker J. S., Heise C. E., Steiner P., J. Biol. Chem., 288, 26926-26943 (2013).

37) Wallace A. C., Laskowski R. A., Thornton J. M., Protein Eng., 8, 127-134 (1995).

38) Jiao J., Fang H., Wang X., Guan P., Yuan Y., Xu W., Eur. J. Med. Chem., 44, 4470-4476 (2009).

39) Morris G. M., Huey R., Lindstrom W., Sanner M. F., Belew R. K., Goodsell D. S., Olson A. J., J. Comput. Chem., 30, 2785-2791 (2009).

40) Pettersen E. F., Goddard T. D., Huang C. C., Couch G. S., Greenblatt D. M., Meng E. C., Ferrin T. E., J. Comput. Chem., 25, 1605$1612(2004)$. 